\title{
Metal-Based Electrocatalysts for High-Performance Lithium-Sulfur Batteries: A Review
}

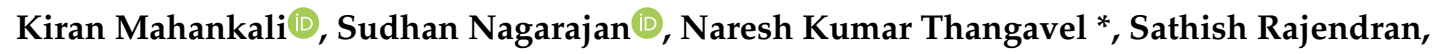 \\ Munaiah Yeddala ${ }^{(D)}$ and Leela Mohana Reddy Arava*
}

Department of Mechanical Engineering, Wayne State University, Detroit, MI 48202, USA;

fx5077@wayne.edu (K.M.); nd.sudhan@wayne.edu (S.N.); sathish1208@wayne.edu (S.R.); hc3249@wayne.edu (M.Y.)

* Correspondence: ge4108@wayne.edu (N.K.T.); leela.arava@wayne.edu (L.M.R.A.)

Received: 11 September 2020; Accepted: 28 September 2020; Published: 1 October 2020

\begin{abstract}
The lithium-sulfur (Li-S) redox battery system is considered to be the most promising next-generation energy storage technology due to its high theoretical specific capacity $\left(1673 \mathrm{mAh} \mathrm{g}^{-1}\right)$, high energy density ( $\left.2600 \mathrm{Wh} \mathrm{kg}^{-1}\right)$, low cost, and the environmentally friendly nature of sulfur. Though this system is deemed to be the next-generation energy storage device for portable electronics and electric vehicles, its poor cycle life, low coulombic efficiency and low rate capability limit it from practical applications. These performance barriers were linked to several issues like polysulfide (LiPS) shuttle, inherent low conductivity of charge/discharge end products, and poor redox kinetics. Here, we review the recent developments made to alleviate these problems through an electrocatalysis approach, which is considered to be an effective strategy not only to trap the LiPS but also to accelerate their conversion reactions kinetics. Herein, the influence of different chemical interactions between the LiPS and the catalyst surfaces and their effect on the conversion of liquid LiPS to solid end products are reviewed. Finally, we also discussed the challenges and perspectives for designing cathode architectures to enable high sulfur loading along with the capability to rapidly convert the LiPS.
\end{abstract}

Keywords: electrocatalysis; lithium-sulfur; metals; metal oxides; metal sulfides; metal carbides

\section{Introduction}

The exponential growth in the utilization of portable electronic devices such as laptops, cellular phones, electric vehicles, etc., has surged the demand for high energy storage devices with extended cycle life. Although lithium-ion (Li-ion) battery technologies have been at the forefront for meeting such needs, they cannot sustain the current global trend of increasing energy demand [1-3]. In this context, the research efforts have been focused on exploring new mechanisms and chemistries, beyond Li-ion batteries, for developing next-generation energy storage systems [2,4]. In search of alternatives over the past few decades, lithium-sulfur (Li-S) battery was identified as one of the most feasible energy storage technology to satisfy the current and near-future energy needs. Li-S battery offers a unique set of advantages such as high theoretical capacity $\left(1672 \mathrm{mAh} \mathrm{g}^{-1}, 10 \mathrm{X}\right.$ times higher energy than the conventional Li-ion battery cathodes), high energy density $\left(\sim 2567 \mathrm{Wh} \mathrm{kg}^{-1}\right)$, low cost and eco-friendliness of sulfur, non-toxicity, and a wide temperature range of operation [5]. The typical Li-S battery's functioning is governed by several highly complex and non-equilibrium multi-step conversion reactions involving various intermediate sulfur species. More specifically, during discharge upon lithiation, the elemental sulfur $\left(\mathrm{S}_{8}\right)$ produces several intermediate lithium polysulfides (LiPS, $\left.\mathrm{Li}_{2} \mathrm{~S}_{\mathrm{n}}, \mathrm{n} \leq 8\right)$ [6]. The long-chain $\mathrm{LiPS}\left(\mathrm{Li}_{2} \mathrm{~S}_{8}\right.$ and $\left.\mathrm{Li}_{2} \mathrm{~S}_{6}\right)$ produced during the initial step of discharge undergoes further reduction to generate medium order LiPS in the midway of discharge. Finally, 
the medium-chain LiPS are converted to solid end products $\left(\mathrm{Li}_{2} \mathrm{~S} / \mathrm{Li}_{2} \mathrm{~S}_{2}\right)$ at the end of the discharge process. The overall reaction can be described by the following equation [7-9]:

$$
16 \mathrm{Li}+\mathrm{S}_{8} \leftrightharpoons 8 \mathrm{Li}_{2} \mathrm{~S}
$$

However, despite several laudable advantages of the Li-S system, its commercialization is severely affected by various performance barriers. First and foremost, the low electrical conductivity of the active material (sulfur) and its final discharge end products $\left(\mathrm{Li}_{2} \mathrm{~S} / \mathrm{Li}_{2} \mathrm{~S}_{2}\right)$ was found to adversely affect the Li-S redox reactions kinetics $[5,10]$. Equivalently, the degradation of the capacity over repeated cycling is considered to be another significant performance barrier. This was mainly attributed to the dissolution of intermediate LiPS, formed during cycling, into the electrolyte originating the LiPS shuttle phenomenon [11-13]. During the shuttle process, the LiPS migrate through the separator to reach the Li metal anode and gets reduced into solid precipitates $\left(\mathrm{Li}_{2} \mathrm{~S} / \mathrm{Li}_{2} \mathrm{~S}_{2}\right)$ on the anode surface, causing self-discharge. Further, the LiPS can shuttle back to the cathode surface, causing a reoxidation reaction. Besides, the formation of insulating charge/discharge end products on the cathode surface, along with the shuttle phenomenon, is found to be responsible for the loss of active material over cycling $[14,15]$. Analogous to the Li-ion batteries, the Li-S system also suffers from uncontrollable Li dendrite growth, which is known to decrease the Coulombic efficiency and eventually lead to internal short-circuit [16-18]. The large volume expansion/contraction of the sulfur cathode during the discharge and charge was found to be yet another major problem in Li-S batteries. The large volume expansion of sulfur was reported to be as high as $\sim 80 \%$ and is regarded as the primary reason for the pulverization of cathode due to the internal strains, finally leading to the delamination between the electrode and current collector [19].

To circumvent these issues, researchers have utilized porous carbon-sulfur composite based materials due to their high electric conductivity, rigidity, and compatibility with sulfur cathodes [20]. Nazar et al. have proposed a strategical mesoporous carbon-sulfur composite that offers a confinement effect for the insulating sulfur [10]. Simultaneously, researchers have attempted to confine sulfur particles within the nanopores of conductive carbon matrix with optimal porosity and high surface area, to suppress the LiPS shuttle [21,22] while improving the cycle life [23-28]. However, non-polar carbonaceous host materials exhibit weak interactions towards highly-polar LiPS, which leads to the eventual dissolution of LiPS. This subsequently resulted in the loss of active material into the electrolyte via diffusion, resulting in severe capacity fade and poor rate capability $[29,30]$. On the other hand, several strategies including oxide and nitride-based cathodes were proposed to effectively curb the LiPS dissolution through chemisorption, the so-called chemical anchoring. For instance, oxides like $\mathrm{Mg}_{0.6} \mathrm{~N}_{0.4} \mathrm{O}$ [31], $\mathrm{Al}_{2} \mathrm{O}_{3}$ [32], $\mathrm{Ti}_{4} \mathrm{O}_{7}$ [33], $\mathrm{MgO}$ [34], $\mathrm{SnO}_{2}$ [35], Al-doped $\mathrm{ZnO}$ [36] were explored which can exhibit strong chemisorption capabilities towards LiPS. Yet, another strategy is to encapsulate the sulfur using oxides like $\mathrm{SiO}_{2}$ [37], $\mathrm{TiO}_{2-x}$ [38], reduced graphene oxide (rGO) [39] and core-shell structures like PANI-S [40], T-HSSP [41], Li 2 S@C [42], CNF [43], carbon/sulfur-cellulose [44], among others [45].

Similarly, York-core-shell structures like sulfur- $\mathrm{TiO}_{2}$ [46], S-PANI [47], G@HMCN [48] were also employed to provide a physical barrier to inhibit LiPS diffusion. More interestingly, a combination of chemical and physical confinement was also reported by Nazar et al., where a sulfur-core $\mathrm{MnO}_{2}$ shell was used as a cathode [49]. Though the various cathode modification strategies discussed overcome the volume change and conductivity issues related to Li-S redox reactions, LiPS diffusion, and the associated shuttling phenomenon is still inevitable. Moreover, the shuttling phenomenon was also found to be responsible for the loss of active material into the electrolyte, which leads to the loss of electrical contact between the LiPS and the electrode surface. Such a process eventually slows down the reaction kinetics of the transformation of LiPS to insoluble discharge end products, which influences the overall LiPS redox process. Additionally, the insulating nature of LiPS, especially the discharge end products $\left(\mathrm{Li}_{2} \mathrm{~S} / \mathrm{Li}_{2} \mathrm{~S}_{2}\right)$, along with their eventual deposition on the electrochemically 
active surface, increases the cell resistance leading to a rise in overpotential and capacity fade upon extended cycling $[15,50]$.

\section{Electrocatalysis of Intermediate LiPS}

Given the multitude of drawbacks associated with the Li-S redox system, either simple entrapment of LiPS or incorporation of conductive backbone in the cathode surface doesn't suffice for its development. Hence, in addition to the already proven adsorption method, accelerating the redox kinetics of the adsorbed LiPS and further entrapment of the charge/discharge end products on the cathode surface emerged as a viable approach to seize the shuttling effect and conquer the challenges such as capacity fade and short cycle life. Traditionally, electrocatalytic electrodes have been employed to enhance the reaction kinetics in electrochemical reactions like hydrogen evolution reaction (HER) [51-53], oxygen evolution reaction (OER) [54], and more often in redox flow cells [55-58]. In Li-S batteries, rapid conversion of liquid intermediate LiPS to solid charge/discharge end products can be facilitated by employing such highly conductive catalytic surfaces by boosting the mass transport and electron transfer rate across the cathode-electrolyte interface [59]. In this context, conventional catalytic surfaces such as platinum $(\mathrm{Pt})$ and nickel $(\mathrm{Ni})$ to electrocatalyze the LiPS conversion reactions have proved to deliver excellent performance along with minimal mass transport issues while showing a drastic enhancement in the rate capability [60-62]. During cycling, these polar natured materials provide anchoring sites for the LiPS, while demonstrating a catalytic effect to enhance the conversion of LiPS to discharge end products. Deploying the concept of electrocatalysis in the highly complex Li-S redox system can thus enable (i) effective entrapment of LiPS (ii) enhancement of LiPS redox kinetics (iii) reduction of polarization (iv) improvement in the specific capacity by several folds (v) realization of excellent reversibility (Figure 1).

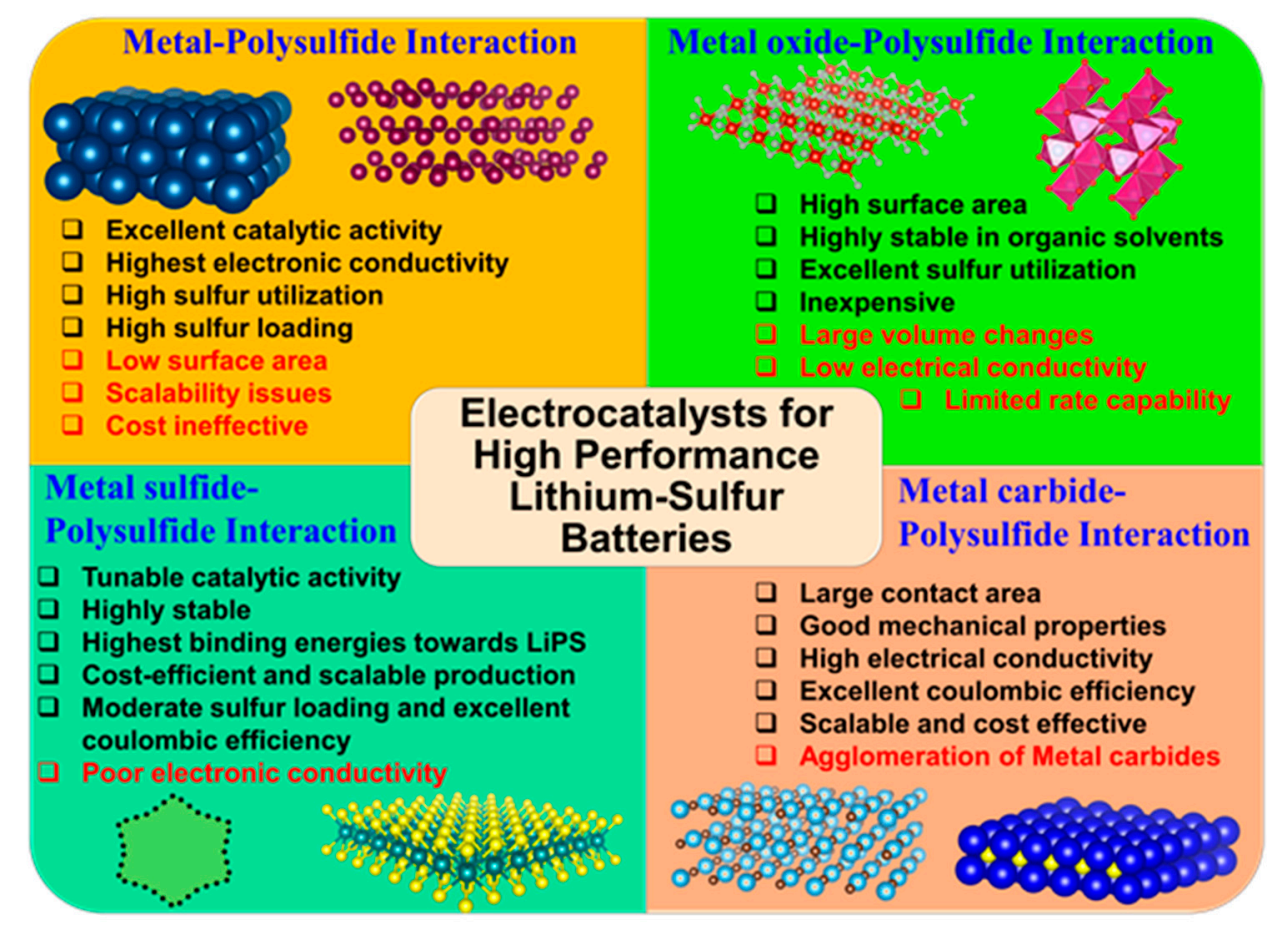

Figure 1. Schematic illustration representing the functions of an electrocatalytic sulfur host in a Li-S battery. The schematic was made using Materials Project Online software (database version 2019.05. Powered by Pymatgen version 2019.10.16) [63,64] and VESTA software [65].

Based on the function and activity, electrocatalysts designed for Li-S are mainly classified into two types (i) homogenous: catalytic active materials are dispersed in the electrolyte, which in turn produces active species that binds to the LiPS and convert them into solid products. (ii) heterogenous: 
cathode surfaces tailored with polarized functional groups that regulate the adsorption and conversion of LiPS into solid ones. Both types of electrocatalysts effectively reduce the charge transfer issues, which leads to the expedited LiPS redox conversion reaction along with less polarization. Additionally, these catalytic materials drastically reduce the internal resistance which arises due to the accumulation of electronically insulating products, by effectively converting them reversibly during charge/discharge. This process is known to vastly improve the Li-S cell performance. However, the homogenous electrocatalyst functions are limited to its electrochemical redox potential and solubility, restricting them from extensive usage. Whereas, being an integral part of the cathode matrix, the robust and cost-effective heterogeneous electrocatalytic surfaces with polar nature has provided widespread opportunity to be explored as cathode hosts for Li-S batteries.

In this approach, the efficiency of the liquid LiPS conversion reaction to solid end products lies in the adsorption mechanism and anchoring effect exhibited by the cathode surface. For instance, the catenation reaction of $\mathrm{MnO}_{2}$ nanosheets with intermediate LiPS via polythionate complex formation was found to accelerate the liquid to solid conversion in a very efficient manner [33]. Similarly, the incorporation of sulfiphilic $\mathrm{CoS}_{2}$ promotes the LiPS adsorption onto the surface while significantly manipulating the redox activity of liquid-liquid LiPS conversion, resulting in the prompt deposition of solid $\mathrm{Li}_{2} \mathrm{~S}$ [59]. Tuning the electrocatalytic surface to lithiophilic/sulfiphilic nature has also provided a widespread opportunity to increase their anchoring or binding affinity towards LiPS. In addition to this, several other parameters such as nucleophilicity, electrophilic character, Lewis acid-base interaction strength, surface polarity determines the anchoring strength of the electrocatalytic surface towards LiPS and thus improves the performance. Previously, the Li-S electrocatalysts have been subjected to review based on recent developments in metal and non-metal based electrocatalytic surfaces [30]. In this review, we classified the electrocatalytic cathodes for Li-S redox reactions based on their interaction with intermediate LiPS. For this purpose, we will discuss metal-sulfide, metal oxide-sulfide, metal sulfide-sulfide, and metal carbide-sulfide based interactions that influence the LiPS anchoring and subsequent redox reactions in detail, with the help of binding energies, extensive adsorption studies. We have compared electrocatalysts with other control electrodes based on cyclic voltammetry (CV) derived parameters like onset potentials for redox reactions, exchange current densities $\left(i_{0}\right)$, etc. Finally, we present our outlook on the development of next-generation electrocatalysts for Li-S batteries.

\section{Metals-Sulfide Interactions in the Electrocatalysis of LiPS Redox Reaction}

Our group has introduced the concept of electrocatalysis for the non-aqueous LiPS reactions [60] by exploring traditional metal-based electrocatalysts such as $\mathrm{Pt}$, gold $(\mathrm{Au})$, and $\mathrm{Ni}$ coated on aluminum (Al) or stainless steel as current collectors while eliminating the need for a carbon matrix (Figure 2a). The Ni electrocatalyst displayed an enhanced $i_{0}$ of $0.071 \mathrm{~mA} \mathrm{~cm}^{-2}$ compared to carbon $\left(0.049 \mathrm{~mA} \mathrm{~cm}^{-2}\right)$, indicating better redox kinetics on the Ni surface. Besides, higher potentials for cathodic reactions and lower potentials for anodic reactions often reflect in low cell polarization as a result of the efficient electrocatalytic activity. Given this information, Table 1 represents a comparison between the redox peak potentials and the exchange current densities of various electrocatalysts compared to control electrodes. In the initial testing, the proposed $\mathrm{Ni}$ and Pt electrocatalysts delivered a discharge capacity of 370 and $395 \mathrm{mAh} \mathrm{g}^{-1}$ at the end of the 50th cycle, respectively. At the same time, Au and Al electrodes exhibited a discharge capacity of only 95 and $25 \mathrm{mAh} \mathrm{g}^{-1}$, respectively. Given that its surface area strongly influences the electrocatalyst's activity [66], the authors attempted to enhance the LiPS conversion reactions on a 3D Ni foam. Li-S assembled with the microporous and macroporous 3D Ni foams exhibited a discharge capacity of 800 and $900 \mathrm{mAh} \mathrm{g}^{-1}$ respectively for 50 cycles, further confirming that the electrocatalysis surface accessibility is maximum with mesoporous structures compared to microporous ones. The same group has also demonstrated the effect of electrocatalyst's (Ni) particle size on the LIPS conversion reaction [67]. In this work, graphene (Gr) supported Ni nanoparticles when used as sulfur hosts, delivered a significantly enhanced discharge capacity over other electrodes under investigation. Detailed studies on these electrodes revealed that the homogeneous distribution 
of Ni nanoparticles within the carbon matrix suppresses their accumulation and loss in surface area during cycling, thus ultimately contributing to the long-lasting synergetic effect of Ni nanoparticles and Gr matrix.
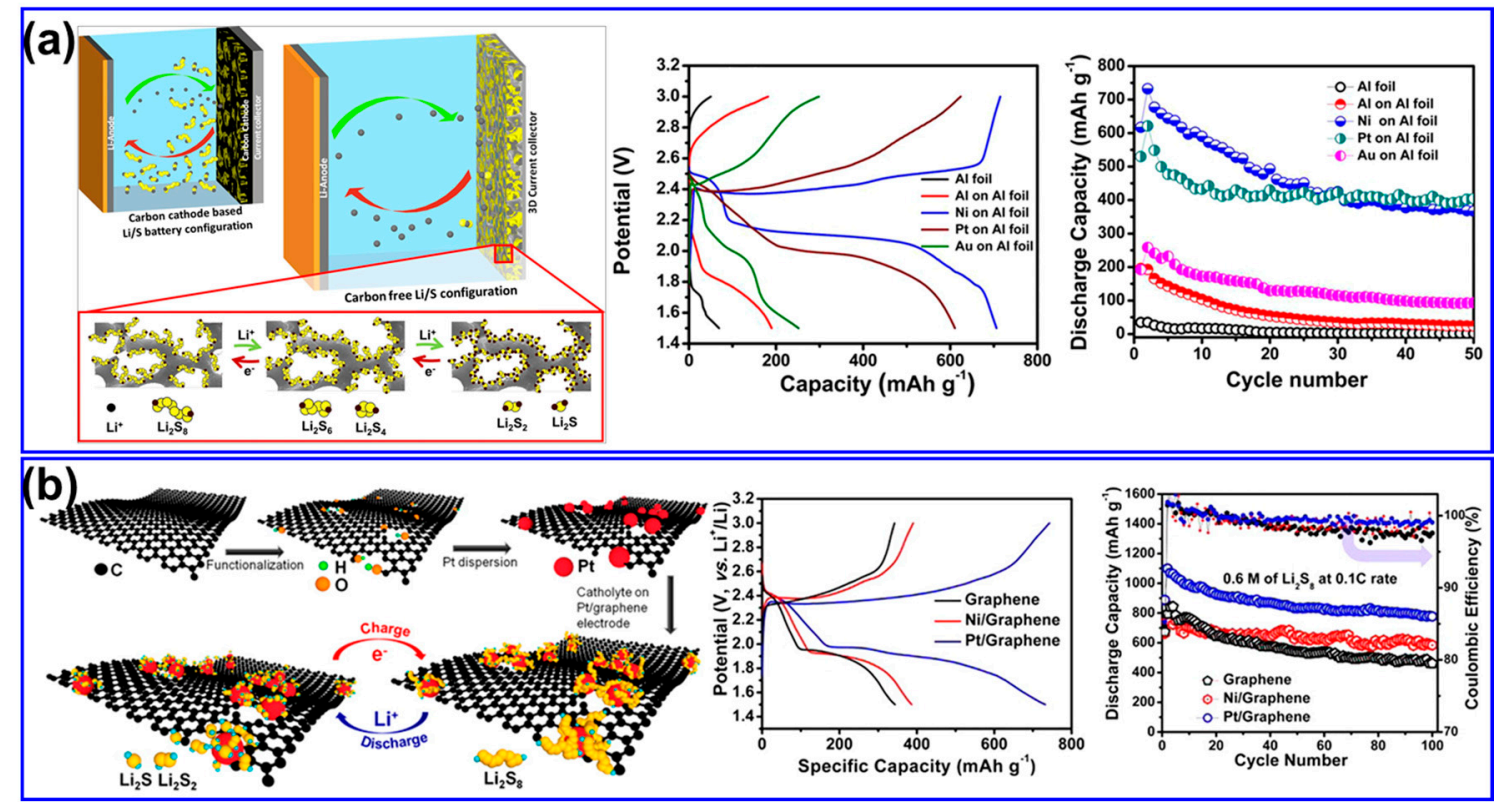

Figure 2. (a) Left: Schematic representation of Li-S battery configuration based on conventional carbonaceous cathode versus novel metal-based current collector (inset representing the anchoring of LiPS on the surface of 3D current collector). Middle: Comparison of charge-discharge plateaus. Right: Cycling behavior of different electrocatalysts on $\mathrm{Al}$ substrate. Reproduced with permission, Copyright, 2015, Springer Nature [60]. (b) Left: Illustration of Pt anchored on graphene nanocomposite preparation and its interaction with LiPS during charge/discharge process. Middle and Right: Charge/discharge plateaus and cycling behavior along with coulombic efficiency of pristine and electrocatalyst anchored graphene electrodes at $0.1 \mathrm{C}$ rate. Reproduced with permission, Copyright, 2015, American Chemical Society [61].

Similarly, Salem et al. have demonstrated the effective utilization of $\mathrm{Pt}$ and Ni nano electrocatalysts in stabilizing the LiPS shuttle (Figure 2b) while ensuring high sulfur loadings [61]. In this work, the authors have attempted to understand the underlying mechanism behind the enhancement in Li-S battery's performance in the presence of nano-electrocatalysts ( $\mathrm{Pt}, \mathrm{Ni}$ ) supported on Gr. For this purpose, ex situ XPS was employed to decipher the interactions between the Pt and LiPS during the charge-discharge processes. The results, on the one hand, revealed the formation of insoluble $\mathrm{Li}_{2} \mathrm{~S}$ and $\mathrm{Li}_{2} \mathrm{~S}_{2}$ on the $\mathrm{Gr}$ surface, both in charged and discharged electrodes, indicating poor reversibility of LiPS. In contrast, XPS results on Pt surface evidenced the limited presence of such products in the charged state along with traces of formation of elemental sulfur. These results demonstrate that unlike the Gr surface, the electrocatalytic Pt binds with the LiPS during the discharge process, which assists in their effective reversibility during the charging process. The catalytic effect on the charge transfer kinetics was demonstrated by the $i_{0}$ values calculated for $\mathrm{Pt} / \mathrm{Gr}$ electrodes, which were found to be $\sim 3$ times (cathodic process) and $\sim 2$ times (anodic process) higher than that of the Gr electrodes. More specifically, the $i_{0}$ calculated for the pristine and Pt/graphene electrodes were found to be 1.18 and $3.18 \mathrm{~mA} \mathrm{~cm}^{-2}$ for the cathodic process and 0.17 and $0.29 \mathrm{~mA} \mathrm{~cm}^{-2}$ for the anodic processes, respectively. Finally, the enhancement in the rate of LiPS conversion reaction due to the electrocatalysis effect [68] was reflected in the excellent specific capacity of the Ni/Gr $\left(740 \mathrm{mAh} \mathrm{g}^{-1}\right)$ and $\mathrm{Pt} / \mathrm{Gr}\left(1100 \mathrm{mAh} \mathrm{g}^{-1}\right)$ electrodes, which correspond to $20 \%$ and $40 \%$ enhancement over pristine Gr electrodes. In a similar effort, Fan et al. have decorated Au nanoparticles (AuNPs) on acetylene black (CB) to be used as a Li-S cathode material (Figure 3a) [69]. Density-functional theory (DFT) 
calculations were employed to understand the interactions between the Li-S discharge products and the AuNPs. The results demonstrated that the chemical bonding between Au with two $\mathrm{Li}$ atoms of $\mathrm{Li}_{2} \mathrm{~S}$ is structurally feasible, and the binding energy between $\mathrm{Li}_{2} \mathrm{~S}$ and $\mathrm{Au}(1.81 \mathrm{eV})$ is several times higher than the binding between $\mathrm{Li}_{2} \mathrm{~S}$ and pristine $\mathrm{CB}(0.37 \mathrm{eV})$. It was anticipated that the AuNPs could form covalent bonds with sulfur or LiPS, effectively limiting the movement of discharge products away from the cathode surface, thus inhibiting the shuttle process. Ex situ XPS analysis was also performed to reveal the nature of chemical interactions between AuNPs and LiPS. The results demonstrated the existence of the Au-S bond in both charge and discharge products on the AuNP electrode indicating their effective anchoring on the catalyst surface. The CV results showed the shortening of electron/ion transfer paths, effective restriction for LiPS, and concurrent catalyzation of electrode reactions by the AuNPs. The cell assembled with AuNPs electrode displayed a reversible discharge capacity of $771 \mathrm{mAh} \mathrm{g}^{-1}$ for over 100 cycles, with a capacity retention of $94.8 \%$ and capacity decay of $0.05 \%$ per cycle; In comparison, the CB-S control electrode delivered a capacity of $297 \mathrm{mAh} \mathrm{g}^{-1}$ only after 100 cycles with $61 \%$ retention. Hence, the decoration of the cathode surface with AuNPs had the following effects on the Li-S battery: (i) improved reaction kinetics due to the significant shortening of the electron transfer paths; (ii) controlled nucleation/reduction of LiPS on the AuNP surface, which minimizes the active material dissolution into the electrolyte and associated wastage. Table 2 summarizes the LiPS adsorption energies of various LiPS on different electrocatalytic surfaces, as revealed by first principle DFT calculations.

Towards deploying electrocatalysts even in a polysulfide full cell configuration, Sawas et al. have reported an electrocatalytically active composite cathode against a 3D porous metallic lithium-free anode to stabilize the LiPS and enhance the reaction kinetics while eliminating the use of unsafe $\mathrm{Li}$ metal anode [70]. For this purpose, Pt functionalized Gr and porous 3-D silicon electrode were used as cathode and anode materials, respectively (Figure 3b). The full cell showed a stable specific capacity of $597 \mathrm{mAh} \mathrm{g}^{-1}$ for over 240 cycles with a minimal capacity loss of $0.147 \%$ per cycle. On the other hand, Gr electrodes displayed a capacity loss of $2.6 \%$ per cycle for the first 10 cycles, followed by $0.54 \%$ loss per cycle for over 130 cycles.

More recently, Chen et al. have shown the synthesis and employment of Co-Fe mixed phosphide nanocubes with highly porous interconnected-pore architecture as Li-S cathode electrodes (Figure 4) [71]. The UV-Vis absorption spectroscopy showed that the Co-Fe-P nanocubes have a robust chemical adsorption capacity towards LiPS, further validated by ex situ XPS studies. Besides, DFT studies revealed that the strong polar-polar interaction behind the $\mathrm{Li}_{2} \mathrm{~S}_{6}$ and $\mathrm{CoP}_{2}$ phase leads to the deformation of the LiPS into three Co-S and two Li-P bonds, whose binding energy $(-3.926 \mathrm{eV})$ towards the electrocatalyst was found to be much higher than towards the conventional carbonaceous electrodes. Besides, LiPS were also found to break and form new bonds with the $\mathrm{FeP}_{2}$ phase of the cathode material whose bindings energies were found to be as high as $-7.40 \mathrm{eV}$. These results indicate the strong chemical trapping ability of nanocubes towards LiPS, while subsequently, these interactions between the cathode material and LiPS dynamically accelerate the kinetics of conversion reactions. As shown in Figure 4, a positive shift in cathodic peaks and a negative shift in anodic peaks for the Co-Fe-P electrode confirms that the LiPS redox kinetics were promoted compared to the Co-Fe electrode. Given these capabilities, the Li-S cells assembled with the nanocubes delivered an initial high specific capacity of $863 \mathrm{mAh} \mathrm{g}^{-1}$ at $1 \mathrm{C}$. In contrast, after long-term cycling for 500 cycles, the capacity was found to be $678 \mathrm{mAh} \mathrm{g}^{-1}$, with an average capacity fade of $0.043 \%$ per cycle. In effect, while the polar characteristics of the nanocubes contribute to the creation of abundant adsorption sites for confining LiPS, their highly interconnected-pore architecture and inherent metallic conductivity further enhanced the redox kinetics of LiPS conversion reactions. 

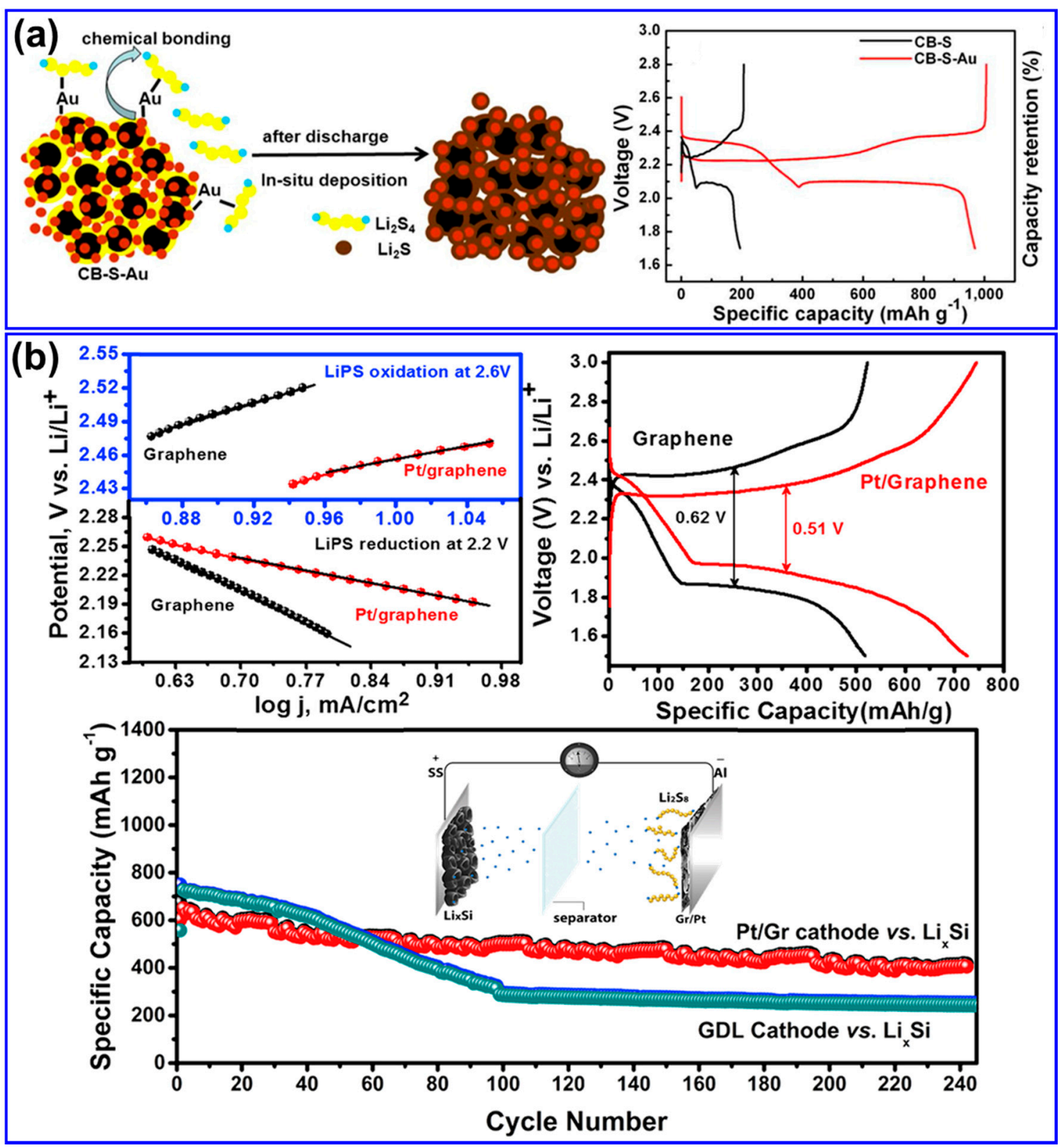

Figure 3. (a) Left: Representation of the functioning mechanism of CB-S-Au cathode. Right: Self-discharge behavior represented by initial charge-discharge profiles of CB-S and CB-S-Au electrodes after storing the cells for 400 hrs. Reproduced with permission, Copyright, 2015, American Chemical Society [69]. (b) Top: Tafel analysis ( $\eta$ vs. $\log j \mathrm{~mA} \mathrm{~cm}{ }^{-2}$ ) on LiPS redox reactions and galvanostatic charge-discharge profiles recorded on pristine graphene and Pt/graphene electrodes. Bottom: Cycling behavior of Li-ion polysulfide battery at 0.5 C rate. Reproduced with permission, Copyright, 2019, Elsevier [70]. 


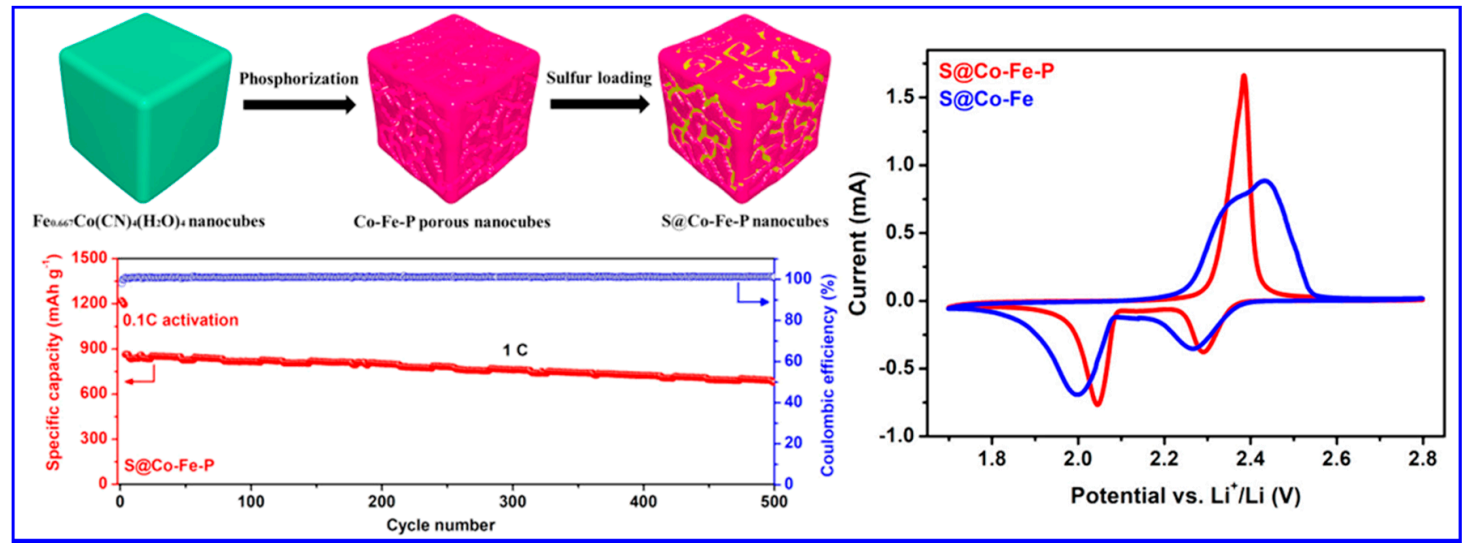

Figure 4. Left top: Illustration of synthesis of S@Co-Fe-P nanocubes. Right: Second cycle CV curves of S@Co-Fe-P and S@Co-Fe cathodes at a scan rate of $0.1 \mathrm{mV} \mathrm{s}^{-1}$. Left Bottom: Long cycling performance and coulombic efficiency of S@Co-Fe-P cathode at $1 \mathrm{C}$ rate. Reproduced with permission, Copyright, 2019, American Chemical Society [71].

Table 1. Summary of cathodic and anodic exchange current densities $\left(i_{0}\right)$, cathodic peak positions observed during cyclic voltammetry $(\mathrm{CV})$ studies for various electrocatalysts. $\mathrm{CNF}$-carbon nanofiber; CNT—carbon nanotube; PG-porous graphene; NS-PC-Nitrogen and sulfur co-doped porous carbon.

\begin{tabular}{|c|c|c|c|c|c|}
\hline $\begin{array}{c}\text { Control Material } \\
\text { and Electrocatalytic } \\
\text { Electrode }\end{array}$ & $\begin{array}{l}\text { Cathodic Exchange } \\
\text { Current Density } \\
\left.(\mathrm{mA} \mathrm{cm})^{-2}\right)\end{array}$ & $\begin{array}{l}\text { Anodic Exchange } \\
\text { Current Density } \\
\quad(\mathrm{mA} \mathrm{cm}-2)\end{array}$ & $\begin{array}{c}\text { Cathodic Peak } \\
\text { Position for } \\
\mathrm{Li}_{2} \mathrm{~S}_{8} \rightarrow \mathrm{Li}_{2} \mathrm{~S}_{4} \\
\left(\mathrm{~V} \text { vs. } \mathrm{Li} / \mathrm{Li}^{+}\right)\end{array}$ & $\begin{array}{l}\text { Cathodic Peak } \\
\text { Position for } \\
\mathrm{Li}_{2} \mathrm{~S}_{4} \rightarrow \mathrm{Li}_{2} \mathrm{~S} / \mathrm{Li}_{2} \mathrm{~S}_{2} \\
\left(\mathrm{~V} \text { vs. } \mathrm{Li} / \mathrm{Li}^{+}\right)\end{array}$ & Ref. \\
\hline Carbon & 0.049 & - & 2.40 & 1.84 & \multirow{2}{*}{ [60] } \\
\hline $\mathrm{Ni}$ & 0.071 & - & 2.43 & 1.94 & \\
\hline Graphene & 1.18 & 0.17 & 2.42 & 1.93 & \multirow{2}{*}{ [61] } \\
\hline Pt on graphene & 3.18 & 0.25 & 2.45 & 1.96 & \\
\hline $\mathrm{CNF}$ & $24 \times 10^{-3}$ & \multirow{3}{*}{-} & & $\sim 2.07$ & \multirow{3}{*}{ [72] } \\
\hline $\mathrm{CNT}+\mathrm{CNF}$ & $35 \times 10^{-3}$ & & - & $\sim 2.08$ & \\
\hline $\mathrm{Mo}+\mathrm{CNT}+\mathrm{CNF}$ & $75 \times 10^{-3}$ & & & 2.11 & \\
\hline PG & 2.28 & 4.81 & 2.32 & 2.03 & \multirow{2}{*}{ [73] } \\
\hline $\mathrm{Fe}_{2} \mathrm{O}_{3}$ on $\mathrm{PG}$ & 3.46 & 4.96 & 2.35 & 2.04 & \\
\hline $\mathrm{NC}$ & - & - & $\sim 2.22$ & $\sim 1.95$ & \multirow{2}{*}{ [74] } \\
\hline $\mathrm{CeO}_{2}$ on $\mathrm{NC}$ & - & - & 2.27 & 2.01 & \\
\hline Carbon & $8.5 \times 10^{-3}$ & - & 2.21 & 1.67 & \multirow{2}{*}{ [62] } \\
\hline $\mathrm{WS}_{2}$ & $11.8 \times 10^{-3}$ & - & 2.24 & 1.78 & \\
\hline Graphene & \multirow[b]{2}{*}{-} & \multirow[b]{2}{*}{ - } & 2.09 & 1.81 & \multirow[b]{2}{*}{ [59] } \\
\hline $\mathrm{CoS}_{2}$ /graphene & & & 2.25 & 2.00 & \\
\hline Carbon cloth & \multirow[b]{2}{*}{ - } & \multirow{2}{*}{-} & 2.30 & 2.05 & \multirow{2}{*}{ [75] } \\
\hline $\mathrm{FeCo}_{2} \mathrm{~S}_{4}$ & & & 2.32 & 1.98 & \\
\hline Carbon & \multirow{2}{*}{-} & \multirow{2}{*}{-} & 2.38 & 1.91 & \multirow{2}{*}{ [76] } \\
\hline $\mathrm{TiC}$ & & & 2.45 & 1.95 & \\
\hline $\mathrm{CNF}$ & \multirow[b]{2}{*}{ - } & \multirow[b]{2}{*}{-} & 2.35 & 2.04 & \multirow{2}{*}{ [77] } \\
\hline $\mathrm{W}_{2} \mathrm{C}-\mathrm{CNF}$ & & & 2.41 & 2.08 & \\
\hline NS-PC & $31.28 \times 10^{-3}$ & $9.29 \times 10^{-3}$ & 2.27 & \multirow[b]{2}{*}{-} & \multirow{2}{*}[78]{} \\
\hline TiC-NS-PC & $42.35 \times 10^{-3}$ & $12.65 \times 10^{-3}$ & 2.34 & & \\
\hline
\end{tabular}

These works demonstrate that the employment of electrocatalysis and, more precisely, the metal catalysts in Li-S batteries can significantly enhance the redox kinetics while curbing the LiPS shuttle. Besides, the inherent high conductivity of the metallic catalysts can also improve contact between the insulating sulfur/discharge end products with the cathode surface, thereby improving the sulfur utilization over prolonged cycling. However, these precious-metal-based electrocatalysts being expensive, low-cost alternative materials are always important from a commercialization point of view. 


\section{Metal Oxide-Sulfide Interactions in Electrocatalysis of LiPS Redox Reactions}

As alternatives to expensive metal catalysts, metal oxide-based surfaces also show excellent electrocatalytic activity towards LiPS adsorption and their subsequent conversion in Li-S batteries. The key point in achieving effective LiPS confinement is the strong interaction between polar natured substrate and the LiPS species during the electrochemical reactions. To date, various metal oxide electrocatalysts including $\mathrm{MnO}_{2}$ [79], $\mathrm{Ti}_{4} \mathrm{O}_{7}$ [33], $\mathrm{MoO}$ [80], $\mathrm{WO}_{3-\mathrm{x}}$ [81], and $\mathrm{CeO}_{2}$ [74], $\mathrm{V}_{2} \mathrm{O}_{5}$ [82], $\mathrm{SnO}_{2}$ [83], $\mathrm{TiO}_{2}$ [84], $\mathrm{ZrO}_{2}$ [85], and $\mathrm{La}_{0.6} \mathrm{Sr}_{0.4} \mathrm{CoO}_{3-\delta}$ [86] have been explored. To entrap LiPS and promote the conversion reactions in Li-S batteries, Linda Nazar and her coworkers introduced a highly efficient LiPS mediatorbased on manganese oxide nanosheet [79]. In this chemical approach, the $\mathrm{MnO}_{2}$ nanosheet mediator facilitated the conversion of LiPS to insoluble $\mathrm{Li}_{2} \mathrm{~S}_{2} / \mathrm{Li}_{2} \mathrm{~S}$ species. The idea is that the host $\mathrm{MnO}_{2}$ nanosheets react with the as-formed LiPS to form surface-based intermediates on the $\mathrm{MnO}_{2}$ surface. Further, polythionates formation was anticipated due to the reaction between LiPS and the surface-bound intermediates. The interaction between sulfur and $\mathrm{MnO}_{2}$ nanosheets was studied by XPS which confirmed the formation of polythionates and thiosulfates during the discharge reaction. With this efficient LiPS conversion reaction, the $\mathrm{MnO}_{2} / \mathrm{S}$ composite delivered high capacity retention of $92 \%$ after 200 cycles at a $C / 5$ rate. Additionally, the cathode exhibited a low capacity fade of $0.036 \%$ per cycle for 2000 charge-discharge cycles at a $2 \mathrm{C}$ rate. Further, to attain an efficient oxide based catalyst with improved electronic conductivity, the same group introduced a highly conductive titanium oxide-based catalyst for LiPS conversion reactions [33]. A Magnéli phase $\mathrm{Ti}_{4} \mathrm{O}_{7}$ based surface-enhanced LiPS redox chemistry was investigated for Li-S batteries. Interestingly, the $\mathrm{Ti}_{4} \mathrm{O}_{7}$ has a high surface area and a high electronic conductivity of the order $2 \times 10^{3} \mathrm{~S} \mathrm{~cm}^{-1}$ at room temperature. Due to its high electrical conductivity and sulfiphilic nature, this metallic oxide exhibits a high affinity towards LiPS which eventually mitigates the LiPS dissolution by forming an effective interface with $\mathrm{Li}_{2} \mathrm{~S}$. More specifically, the study elucidated the interactions between $\mathrm{Ti}_{4} \mathrm{O}_{7}$ surface with both the terminal and bridging sulfur in the LiPS, which leads to the polarization of electrons away from the sulfur atom and towards titanium and/or oxygen vacancies (which are inherently electropositive). Additionally, the surface-mediated redox between LiPS and the sulfiphilic metal oxide host was extensively studied by XPS and X-ray Absorption Near Edge Structure, evidencing the accelerated conversion of LiPS to $\mathrm{Li}_{2} \mathrm{~S}$ through the interaction between sulfiphilic host and LiPS compared to the carbon surface. With this excellent catalytic activity, the $\mathrm{Ti}_{4} \mathrm{O}_{7} / \mathrm{S}$ composite cathode exhibited a discharge capacity of $1070 \mathrm{mAh} \mathrm{g}^{-1}$ at a moderate rate and delivered a stable cycle life of 500 cycles at $2 \mathrm{C}$ rate.

To improve the oxide catalyst conductivity, Zheng et al. introduced a $\mathrm{Fe}_{2} \mathrm{O}_{3} / \mathrm{Gr}$ hybrid prepared by introducing $\mathrm{Fe}_{2} \mathrm{O}_{3}$ nanoparticles onto $\mathrm{Gr}$ nanosheets via a one-pot strategy [73]. Due to the strong interaction between LiPS and $\mathrm{Fe}_{2} \mathrm{O}_{3}$ nanoparticles, the LiPS shuttle was mitigated. The conversion of soluble LiPS to insoluble $\mathrm{Li}_{2} \mathrm{~S}_{2} / \mathrm{Li}_{2} \mathrm{~S}$ was also accelerated, thus improving the sulfur utilization. Detailed DFT calculations to understand the interactions between the LiPS and $\mathrm{Fe}_{2} \mathrm{O}_{3}$ revealed that the electrocatalyst showed adsorption energies at least 3 times higher than Gr towards all LiPS, $\mathrm{S}_{8}$ and $\mathrm{Li}_{2} \mathrm{~S}$. Further, the binding mechanism of LiPS on different surfaces was illustrated as: (i) only weak Van der Waals interaction exists between $\mathrm{S}$ clusters and $\mathrm{Gr}$ (ii) strong $\mathrm{Li}-\mathrm{O}$ and $\mathrm{Fe}-\mathrm{S}$ bonds are responsible for the high binding energy in the case of $\mathrm{Fe}_{2} \mathrm{O}_{3}$ surface, which tends to further increase with shortening sulfur chains. The 3D Gr network improved the electronic conductivity and enhanced the electron transfer while providing enough space for volume expansion during charge-discharge reactions. The $i_{0}$ calculated from potentiostatic polarization experiments for the $\mathrm{Fe}_{2} \mathrm{O}_{3}$ electrode displayed a value of 3.46 and $4.96 \mathrm{~mA} \mathrm{~cm}^{-2}$ for the cathodic and anodic processes, respectively, which was found to be higher than the porous graphene electrode $\left(2.28\right.$ and $\left.4.81 \mathrm{~mA} \mathrm{~cm}^{-2}\right)$. The improved $i_{0}$ indicates an enhanced rate of intermediate LiPS conversion into discharge end products during the charge and discharge processes. The sulfur $/ \mathrm{Fe}_{2} \mathrm{O}_{3}$ hybrid exhibited a high capacity of $565 \mathrm{mAh} \mathrm{g}^{-1}$ with a low capacity decay of $0.049 \%$ per cycle for 1000 continuous charge-discharge cycles at $5 \mathrm{C}$ rate. Another exciting strategy of separator modification using $\mathrm{MoO}_{3}$ nanobelts for electrocatalysis of LiPS 
was carried out by James A. Anderson and his coworkers [80]. In this different approach, the $\mathrm{MoO}_{3}$ nanobelt modified separator exhibited a bifunctional catalytic effect for the chemical encapsulation and electrocatalytic conversion of LiPS (Figure 5a). Further, a strong chemical interaction between the LiPS and $\mathrm{MoO}_{3}$ successfully blocked the LiPS on the separator and catalyzed the redox reaction of LiPS on the cathode side. The electrocatalytic effect was evidenced from CV curves, where the $\mathrm{MoO}_{3}$ modified separator showed a significant increment in the current density during $\mathrm{CV}$ compared to the pristine separator. In effect, the $\mathrm{MoO}_{3}$ modified separator delivered a high capacity of $684 \mathrm{mAh} \mathrm{g}^{-1}$ at $0.5 \mathrm{C}$ rate for 200 cycles.
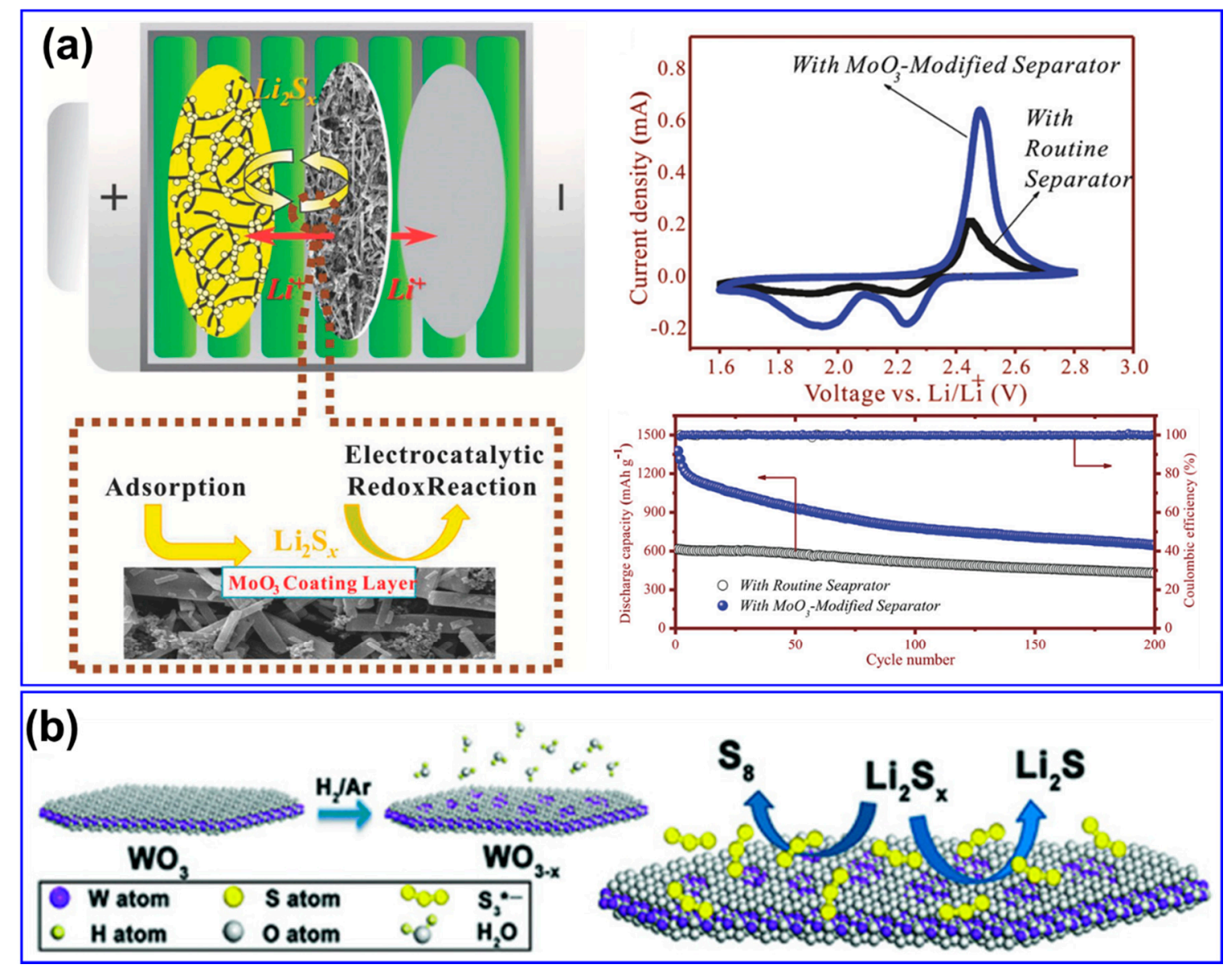

Figure 5. (a) Left: Schematic of the $\mathrm{MoO}_{3}$ modified separator configuration in Li-S batteries. Right top and bottom: CV curves and cycling performance of Li-S battery with and without $\mathrm{MoO}_{3}$ modified separator. Reproduced with permission, Copyright 2018, Wiley [80]. (b) Top: Schematic illustration of the synthesis of $\mathrm{WO}_{3}$ and oxygen-deficient $\mathrm{WO}_{3}$ and the conversion mechanism of $\mathrm{Li}_{2} \mathrm{~S}_{\mathrm{x}}$ on the $\mathrm{WO}_{3-\mathrm{x}}$ surface. Reproduced with permission, Copyright, 2018, Wiley [81].

It is well known that oxygen deficiency in oxide-based cathodes is known to exhibit excellent electrocatalytic activity towards any electrochemical reactions $[87,88]$. In this context, to elucidate the cationic activity of oxygen deficiency on the LiPS conversion, oxygen-deficient $\mathrm{WO}_{3}$ nanoplates were proposed as electrocatalysts for Li-S batteries [81]. In this work, $\mathrm{WO}_{3}$ was taken as a model compound, and the catalytic effect of oxygen deficiency was elucidated using a self-doped oxide without any heteroatoms. Additionally, the $\mathrm{WO}_{3}$ is a low-cost material compared to other metallic electrocatalysts, and the oxygen-deficient $\mathrm{WO}_{3}$ can be synthesized easily (Figure $5 \mathrm{~b}$ ). The beneficial catalytic activity of accelerated LiPS conversion was investigated using UV-Vis spectroscopy, which demonstrated that the oxygen deficiency in $\mathrm{WO}_{3}$ interacts with the LiPS and significantly mitigates the accumulation of LiPS 
in the sulfur cathode surface. As a result, the $\mathrm{S} / \mathrm{WO}_{3}$ nanoplate cathode exhibited a capacity decay of only $0.13 \%$ per cycle at a $0.5 \mathrm{C}$ rate.

Further, to achieve effective confinement of sulfur, a $\mathrm{CeO}_{2}$ nanocrystal was implanted homogeneously into a bimodal mesoporous nitrogen-doped carbon sphere $\left(\mathrm{CeO}_{2} / \mathrm{MMNC}\right)$, as shown in Figure 6 [74]. The $\mathrm{CeO}_{2} / \mathrm{MMNC}$ showed key characteristics, especially the hybrid material has high porosity, polar adsorption sites, 3D nanochannels, and high electronic conductivity. With the advantage of physical and chemical interactions with LiPS, the polar and conductive nanocrystal catalyst significantly mitigated the LiPS dissolution and facilitated the fast LiPS conversion reactions. In the present work, the strong electrocatalytic effect along with enhanced LiPS redox kinetics on $\mathrm{CeO}_{2}$ nanocrystals was confirmed by the positive and negative shifts in the reduction and oxidation peaks of $\mathrm{CV}$ respectively. By combining the synergetic effect of LiPS adsorption and LiPS fast reaction kinetics, the $\mathrm{CeO}_{2} / \mathrm{MMNC}$ cathode with $1.4 \mathrm{mg} \mathrm{cm}^{-2}$ loading exhibited a reversible capacity of $1064 \mathrm{mAh} \mathrm{g}^{-1}$ at $0.2 \mathrm{C}$ rate after 200 cycles. Interestingly, a highly stable cycle life of $721 \mathrm{mAh} \mathrm{g}^{-1}$ capacity at $2 \mathrm{C}$ rate has achieved 1000 cycles at a low capacity decay of $0.024 \%$ per cycle. Moreover, high loading of $3.4 \mathrm{mg} \mathrm{cm}^{-2}$ cathode was also investigated, and stable capacity of $611 \mathrm{mAh} \mathrm{g}^{-1}$ was achieved after 200 cycles.

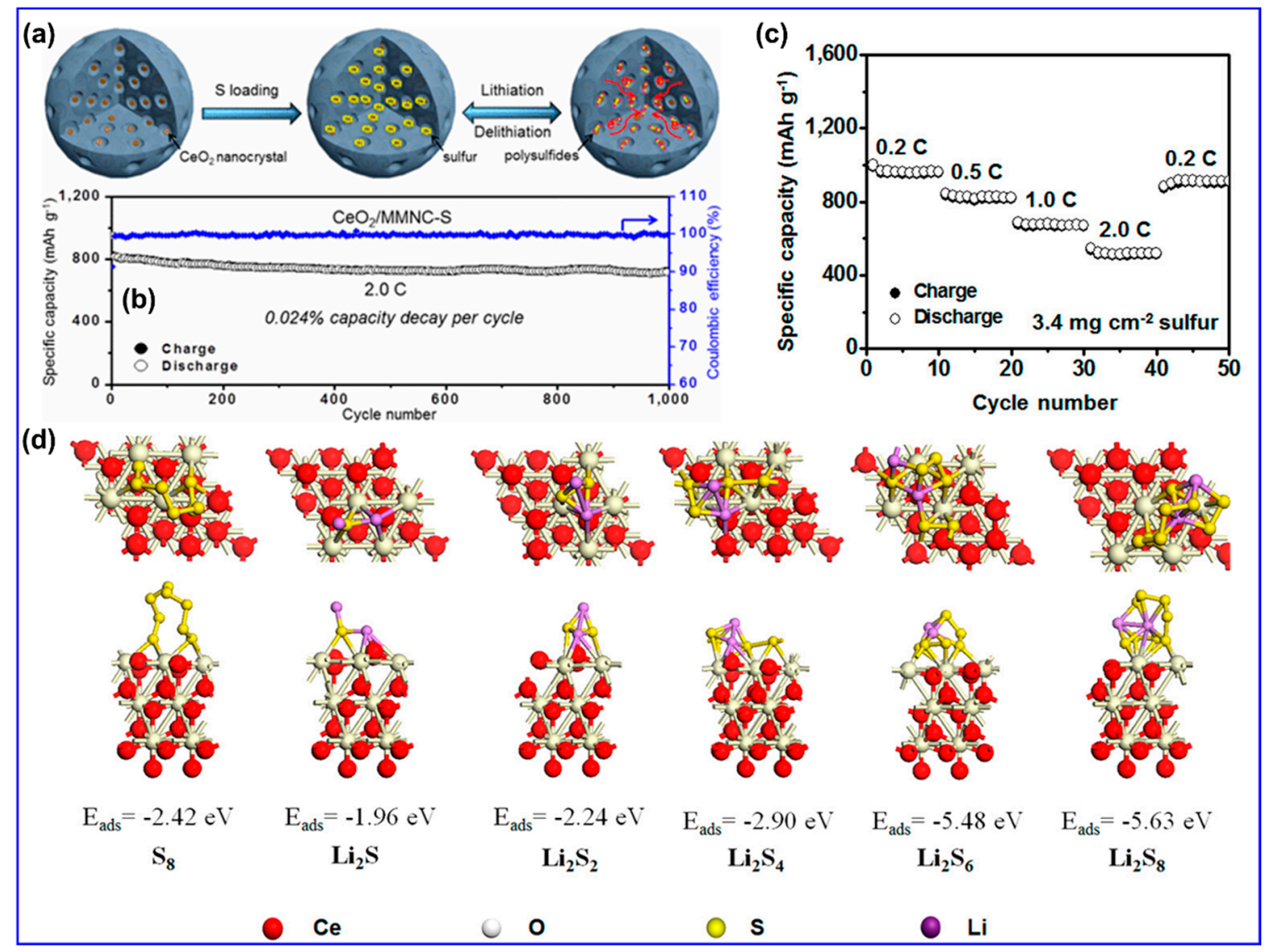

Figure 6. (a) Schematic representation of the functioning of $\mathrm{CeO}_{2}$ nanospheres as sulfur hosts. (b) Cycling performance and corresponding coulombic efficiency. (c) Rate performance of $\mathrm{CeO}_{2}$ cathode. (d) Binding geometric configurations and binding energies of $\mathrm{LiPS}, \mathrm{Li}_{2} \mathrm{~S}$, and $\mathrm{S}_{8}$ with the (111) plane of $\mathrm{CeO}_{2}$ nanocrystals. Reproduced with permission, Copyright, 2017, American Chemical Society [74].

\section{Metal Sulfides-Sulfide Interactions in Electrocatalysis of LiPS Redox Reactions}

Inspired by their application in desulfurization [89], solar cells [90], and hydrogen evolution reaction [91], cost-effective and non-noble metal-based chalcogenide electrocatalysts have attracted 
immense attention due to their excellent performance toward sulfur chemistries. In general, sulfide-based transition metal electrocatalysts has several advantages: (i) they offer high stability towards sulfur chemistries, (ii) their sulfiphilic nature is highly attractive towards LiPS, (iii) they avoid overlapping with the active voltage region in Li-S batteries due to its low lithiation potentials [30]. Additionally, the sulfide-based electrocatalysts are generally metallic or semi-metallic, which further assists in facile electron transfer during LiPS conversion reactions. Furthermore, the basis behind their electrocatalytic property is that the effective $\mathrm{d}$ band structure is obtained by the synergism between metal d orbital and unsaturated S heteroatom, thereby approaching the $\mathrm{d}$ band of Pt. In general, the catalytic activity of the metal sulfide materials is correlated to the number of exposed edge sites [92]. To date, numerous sulfide-based electrocatalysts have been explored for LiPS conversion reactions, especially $\mathrm{CoS}_{2}, \mathrm{WS}_{2}, \mathrm{MoS}_{2}, \mathrm{SnS}_{2}$, and binary sulfides [93].

Table 2. Binding energies (eV) between various electrocatalysts and LiPS, obtained from first principle DFT calculations.

\begin{tabular}{|c|c|c|c|c|c|c|c|}
\hline & Material & $\mathrm{Li}_{2} \mathrm{~S}(\mathrm{eV})$ & $\mathrm{Li}_{2} \mathrm{~S}_{4}(\mathrm{eV})$ & $\mathrm{Li}_{2} \mathrm{~S}_{6}(\mathrm{eV})$ & $\mathrm{Li}_{2} \mathrm{~S}_{8}(\mathrm{eV})$ & $\mathrm{S}_{8}(\mathrm{eV})$ & Ref. \\
\hline Non-metal & Graphene & 0.65 & 0.72 & 0.93 & 1.10 & 0.89 & [73] \\
\hline \multirow{3}{*}{ Metal } & Gold nanoparticles & 1.81 & - & - & - & - & [69] \\
\hline & Co-Fe-P & - & - & $\begin{array}{l}-3.92(\mathrm{Co}-\mathrm{S}) \\
-7.40\left(\mathrm{FeP}_{2}\right)\end{array}$ & - & - & [71] \\
\hline & Bismuth & -2.36 & -0.45 & -0.32 & -0.39 & - & [94] \\
\hline \multirow{3}{*}{ Metal oxides } & $\mathrm{Fe}_{2} \mathrm{O}_{3}$ & 4.85 & 4.09 & 4.11 & 3.78 & 2.04 & [73] \\
\hline & $\mathrm{CeO}_{2}$ & -1.96 & -2.90 & -5.48 & -5.63 & -2.42 & [74] \\
\hline & $\mathrm{LiNi}_{0.8} \mathrm{Co}_{0.1} \mathrm{Mn}_{0.1} \mathrm{O}_{2}$ & - & - & -2.25 & - & - & [95] \\
\hline \multirow{7}{*}{ Metal Sulfides } & $\mathrm{CoS}_{2}$ & - & 1.97 & - & - & - & [59] \\
\hline & $\mathrm{Fe}_{7} \mathrm{~S}_{8}$ & - & -4.25 & -4.33 & -5.00 & - & [96] \\
\hline & $\mathrm{Ni}_{3} \mathrm{~S}_{2}$ & 4.89 & 2.29 & 2.15 & 1.92 & 1.09 & [97] \\
\hline & $\mathrm{Co}_{3} \mathrm{~S}_{4}$ & - & 2.26 & 1.61 & 1.68 & - & [98] \\
\hline & $1 \mathrm{~T}-\mathrm{MoS}_{2}$ & $\sim 1.25$ & $\sim 1.15$ & $\sim 1.30$ & $\sim 1.45$ & $\sim 1.28$ & [99] \\
\hline & $\mathrm{MoS}_{2}$ & 0.87 & 0.32 & 0.22 & 0.10 & 0.05 & [100] \\
\hline & $\mathrm{FeCO}_{2} \mathrm{~S}_{4}$ & -6.61 & -4.50 & -3.94 & -5.21 & - & [75] \\
\hline \multirow{4}{*}{ Metal Carbides } & $\mathrm{TiC}$ & - & - & - & 3.68 & - & [76] \\
\hline & TiC-N-S-C & -3.80 & -4.00 & -2.00 & -3.50 & - & [78] \\
\hline & $\mathrm{W}_{2} \mathrm{C}$ & - & - & -2.57 & - & - & [77] \\
\hline & $\mathrm{B}_{4} \mathrm{C}(100)$ facet & - & 12.51 & - & - & - & [101] \\
\hline
\end{tabular}

Our group introduced transition metal sulfides as electrocatalysts for alleviating the shuttling process in Li-S batteries through adsorption of LiPS on edge sites (Figure 7a) [62]. The $\mathrm{WS}_{2}$ catalyst as a host for LiPS conversion reaction has several advantages (i) since there is no physical encapsulation of LiPS, the Li-ion transport will not be impeded, (ii) the production of non-noble metal-based $\mathrm{WS}_{2}$ is cost-effective and can also be scaled up further for low-cost Li-S batteries. Due to its intrinsic physicochemical properties, the detrimental LiPS shuttle reaction was significantly stabilized. Further, as evidenced by $\mathrm{CV}$, the onset potential for the reduction reactions was found to be higher (2.24 and $1.78 \mathrm{~V})$ on the $\mathrm{WS}_{2}$ surface compared to the carbon surface $(2.21$ and $1.67 \mathrm{~V})$. Additionally, the $i_{0}$ was found to be $11.8 \mu \mathrm{A} \mathrm{cm}^{-2}$ for $\mathrm{WS}_{2}$, while it was only $8.5 \mu \mathrm{A} \mathrm{cm}^{-2}$ on the carbon surface, indicating that catalytic active edge sites of $\mathrm{WS}_{2}$ enhanced the charge transfer kinetics. The interaction between LiPS and $\mathrm{WS}_{2}$ edge sites was visualized through systematic scanning electron microscopy (SEM) studies and further evidenced by spectroscopy measurements such as XPS and UV-Vis. The adsorption results demonstrate that unsaturated edge atoms of transition metal dichalcogenide (TMDs) exhibited significant LiPS adsorption due to polarity and inherent catalytic activity. As a result, a specific capacity of $590 \mathrm{mAh} \mathrm{g}^{-1}$ and catalytic driven stable coulombic efficiency of $99 \%$ for 350 continuous charge-discharge cycles was realized. 

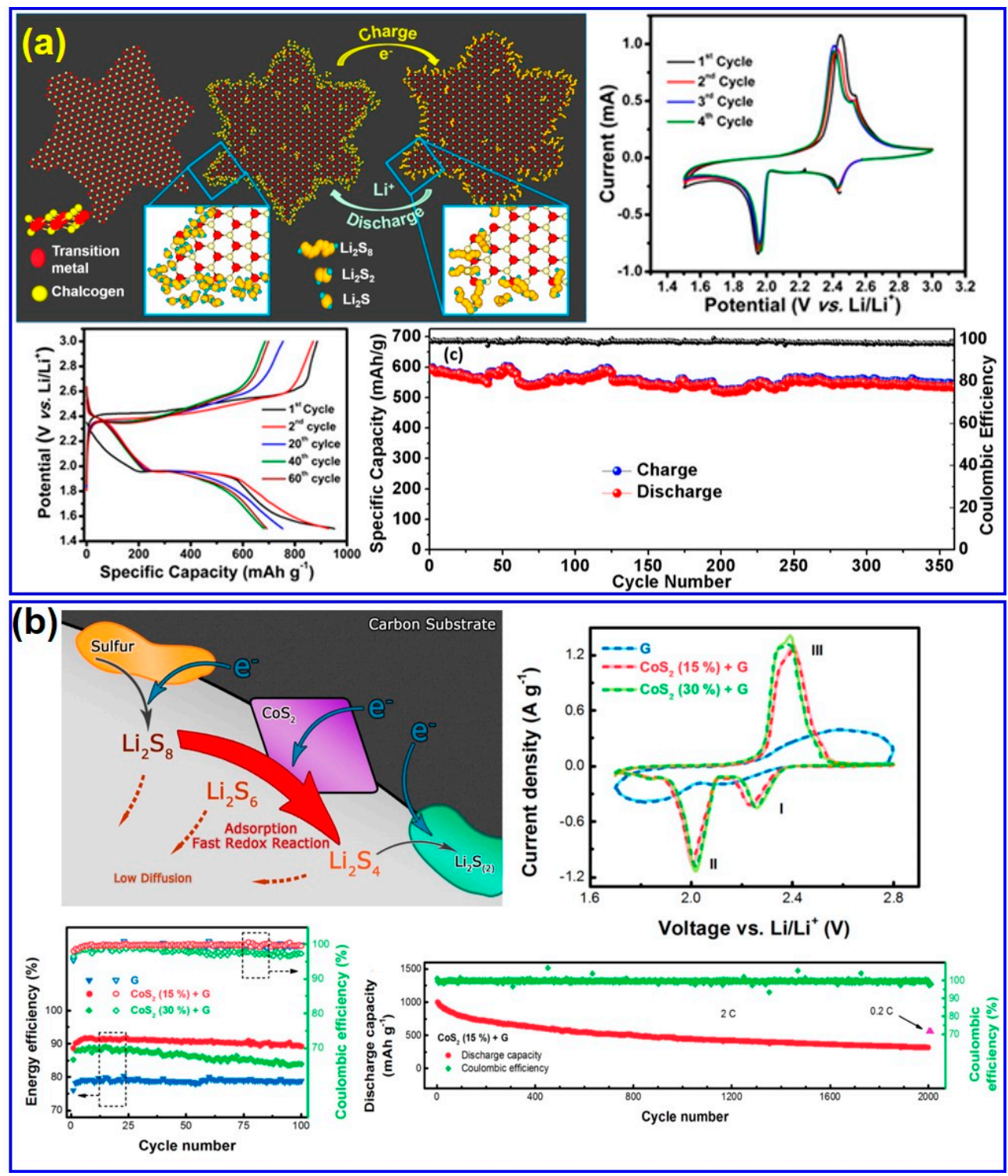

Figure 7. (a) Top left: Schematic representation of chemical vapor deposition (CVD)-grown atomically thin layered $\mathrm{WS}_{2}$ nanosheets for Li-S batteries. Top right and bottom: Electrochemical studies of CVD-grown $\mathrm{WS}_{2}$ nanosheets in Li-S batteries. Reproduced with permission, Copyright, 2016, American Chemical Society [62]. (b) Top left: schematic illustration of polysulfide conversion reaction using $\mathrm{CoS}_{2}$ incorporated sulfur cathode. Top right and bottom: Cyclic voltammetry and cycling studies on the $\mathrm{CoS}_{2}$ electrode. Reproduced with permission, Copyright, 2016, American Chemical Society [59].

Zhang and his coworkers introduced $\mathrm{CoS}_{2}$ as an efficient LiPS conversion electrocatalyst in Li-S batteries (Figure 7b) [59]. The $\mathrm{CoS}_{2}$ is a pyrite mineral and semi-metallic in nature with a conductivity of $6.7 \times 10^{3} \mathrm{~S} \mathrm{~cm}^{-1}$ at $300 \mathrm{~K}$, which is relatively high compared to the first-row transition metal sulfides such as $\mathrm{Ni}_{3} \mathrm{~S}_{2}$ and $\mathrm{FeS}_{2}$. Given the sulfiphilic nature and high electron conduction property of $\mathrm{CoS}_{2}$, its incorporation could accelerate LiPS redox reactions in Li-S batteries. In addition to the conventional CV for a typical Li-S cell, to investigate the redox kinetics of LiPS, the authors studied the electrocatalyst in a symmetrical cell format containing active material in the form of $\mathrm{Li}_{2} \mathrm{~S}_{6}$. From the $\mathrm{CV}$, it is clear that as the $\mathrm{CoS}_{2}$ weight ratio increases, the current density is increased by order of magnitude, indicating that the $\mathrm{CoS}_{2}$-LiPS interactions accelerated the LiPS conversion reactions compared to the $\mathrm{Gr}$ surface. More importantly, DFT calculations revealed the $\mathrm{Li}_{2} \mathrm{~S}_{4}$ binding mechanism to $\mathrm{CoS}_{2}$ as follows: (i) initially, the $\mathrm{Li}$ atoms and terminal sulfur atoms of $\mathrm{Li}_{2} \mathrm{~S}_{4}$ orients towards sulfur dimers and Co atoms 
of $\mathrm{CoS}_{2}$ due to the electrostatic affinities of the donor-acceptor pairs; (ii) simultaneously, S-S bridge of $\mathrm{Li}_{2} \mathrm{~S}_{4}$ positions far away from the $\mathrm{CoS}_{2}$ surface, which enables the large charge density atoms to occupy the spaces close to its surface; (iii) these concurrent processes ultimately lead to the generation of sufficient charge transfer and very high binding energy of $1.97 \mathrm{eV}$ between $\mathrm{Li}_{2} \mathrm{~S}_{4}$ and $\mathrm{CoS}_{2}$. In contrast, the absence of polarized charge distribution on the Gr surface is responsible for low atomic interactions and low binding energy of only $0.34 \mathrm{eV}$ with $\mathrm{Li}_{2} \mathrm{~S}_{4}$. In short, the thermally reduced $\mathrm{CoS}_{2} / \mathrm{Gr}$ composite employed in the LiPS conversion reaction exhibited accelerated LiPS redox kinetics, low polarization effects, and high energy efficiency under high currents. Overall, the composite promoted Li-S battery delivered a discharge capacity of $60 \%$ and an improved energy efficiency of $10 \%$. Further, an improved cycle life was achieved at a high current density of $2 \mathrm{C}$ rate with a low capacity decay rate of only $0.034 \%$ per cycle for over 2000 continuous charge-discharge cycles.

To explore more conductive LiPS adsorbents, Pu et al. investigated the hydrothermal synthesized conductive $\mathrm{Co}_{3} \mathrm{~S}_{4}$ nanotubes for Li-S batteries [98]. In general, a highly conductive LiPS adsorbent with a high aspect ratio is the critical design strategy for highly efficient sulfur cathodes. To achieve a continuous conductive network, nanotube morphology-based $\mathrm{Co}_{3} \mathrm{~S}_{4}$ with high electronic conductivity was synthesized and investigated as a sulfur host in Li-S batteries. The nanostructured and conductive $\mathrm{Co}_{3} \mathrm{~S}_{4}$ helped to host sulfur species and catalyzed the sulfur species by relatively large surface area. Further, the authors have employed symmetrical cell studies to elucidate the enhanced electrochemical properties of $\mathrm{Co}_{3} \mathrm{~S}_{4}$ nanotubes. Chronoamperometric studies on these cells revealed a higher current response upon the addition of $\mathrm{Li}_{2} \mathrm{~S}_{6}$ in the electrolyte in comparison to its absence, indicating the current response is dominated by the lithiation/delithiation reactions rather than double-layer capacitance. Similarly, CV studies with $\mathrm{Li}_{2} \mathrm{~S}_{6}$ also presented higher current response in the case of $\mathrm{Co}_{3} \mathrm{~S}_{4}$ compared to the acetylene black electrode, depicting that the electrocatalyst performs two essential functions: (i) absorb sulfur species (ii) accelerate the LiPS electrochemical conversion reactions. Additionally, the high electronic conductivity of the $\mathrm{Co}_{3} \mathrm{~S}_{4}$ nanotubes assisted in the acceleration of the sulfur reaction kinetics. As a result, it exhibited a high capacity of $1024 \mathrm{mAh} \mathrm{g}^{-1}$ at $0.05 \mathrm{C}$ while displaying a slow capacity decay of only $0.04 \%$ per cycle at a very high rate of $5 \mathrm{C}$ rate for over 1000 cycles.

A metal-organic frameworks (MOF) derived efficient multifunctional $\mathrm{Co}_{9} \mathrm{~S}_{8}$ was grown directly on a separator to be used as a polar barrier in Li-S batteries, using a liquid reaction-based approach [102]. The in situ grown $\mathrm{Co}_{9} \mathrm{~S}_{8}$ works as a LiPS polar barrier and improves the LiPS blocking. With this improved strategy, the fabricated pouch cell using $\mathrm{Co}_{9} \mathrm{~S}_{8}$ grown separator delivers a high capacity of $1200 \mathrm{mAh} \mathrm{g}^{-1}$ for 30 charge-discharge cycles. In another report, a self-template synthesis of metallic and polar $\mathrm{Co}_{9} \mathrm{~S}_{8} / \mathrm{C}$ hollow polyhedra was investigated as a sulfur host in Li-S batteries [103]. The nano polyhedra were synthesized from a facile sulfurization, followed by a melt diffusion process. The hollow polyhedra have numerous advantages: (i) a high sulfur loading can be achieved from highly porous void space, (ii) the nano polyhedral is metallic and highly polar in nature, leading the $\mathrm{Co}_{6} \mathrm{~S}_{8}$ to strongly bind to LiPS and improve the reaction kinetics, and (iii) the $3 \mathrm{D}$ porous $\mathrm{Co}_{6} \mathrm{~S}_{8} / \mathrm{C}$ composite improves the Li-ion transport through conductive outer shells. In effect, the nano polyhedra with high surface area delivered a high capacity of $950 \mathrm{mAh} \mathrm{g}^{-1}$ at $0.1 \mathrm{C}$ rate and a low capacity decay of $0.041 \%$ per cycle for 1000 cycles at $2 \mathrm{C}$ rate.

A liquid phase exfoliated, low-cost $\mathrm{MoS}_{2}$ based electrode was also investigated for high-performance Li-S batteries [104], where a controlled amount of sulfur deficiencies on the $\mathrm{MoS}_{2-\mathrm{x}} / \mathrm{rGO}$ catalytic surface catalyzed the LiPS conversion reactions (Figure 8a). CV studies on symmetric cells were carried out to understand the catalytic effect of $\mathrm{MoS}_{2-\mathrm{x}}$ on the LiPS redox reactions. As shown in Figure 8b, the CVs revealed distinctive highly reversible peaks representing reduction $(-0.047$ and $-0.39 \mathrm{~V})$ and the oxidation process $(0.047$ and $0.39 \mathrm{~V})$ of $\mathrm{Li}_{2} \mathrm{~S}_{6}$. In comparison, $\mathrm{MoS}_{2} / \mathrm{rGO}$ and bare rGO electrodes only displayed indistinct and drawn-out redox peaks. It is noteworthy that the sharp peaks and narrow peak separation in the case of the $\mathrm{MoS}_{2-x}$ electrode represent excellent electrochemical reversibility and facile LiPS conversion reactions. Consequently, the accelerated LiPS conversion controlled the accumulation of discharge products on the cathode surface, indicating that the 
sulfur utilization was improved by fast LiPS conversion kinetics. With this kinetic effect, sulfur with a small amount of $\mathrm{MoS}_{2}$ delivered an excellent cycle life of 1600 cycles at a $5 \mathrm{C}$ rate with a $0.083 \%$ capacity decay per cycle. The result indicates that the low cost and facile synthesis of $\mathrm{MoS}_{2}$ based electrode could be an excellent catalyst for LiPS conversion in Li-S batteries. Furthermore, to develop polar LiPS adsorbent with high sulfur loading, Gao et al. developed Co-doped $\mathrm{SnS}_{2}$ anchored on nitrogen-doped CNT as sulfur host for Li-S batteries [105]. The nanostructured NCNT-Co-SnS 2 was synthesized by a spray pyrolyzed method coupled with a solvothermal reaction. Since Co compounds have an excellent affinity towards LiPS and exhibit an excellent activity towards LiPS conversion, the authors enhanced the LiPS conversion reaction by employing $\mathrm{SnS}_{2}$ using Co doping and nitrogen-doped conductive carbon nanotube. With the synergetic effect of Co's catalytic activity towards LiPS and $\mathrm{SnS}_{2} \mathrm{LiPS}$ adsorption effects, the sulfur loaded NCNT-Co-SnS 2 exhibited a specific capacity of $1351 \mathrm{mAh} \mathrm{g}^{-1}$ at $13 \mathrm{~mA} \mathrm{~cm}^{-2}$ current density.
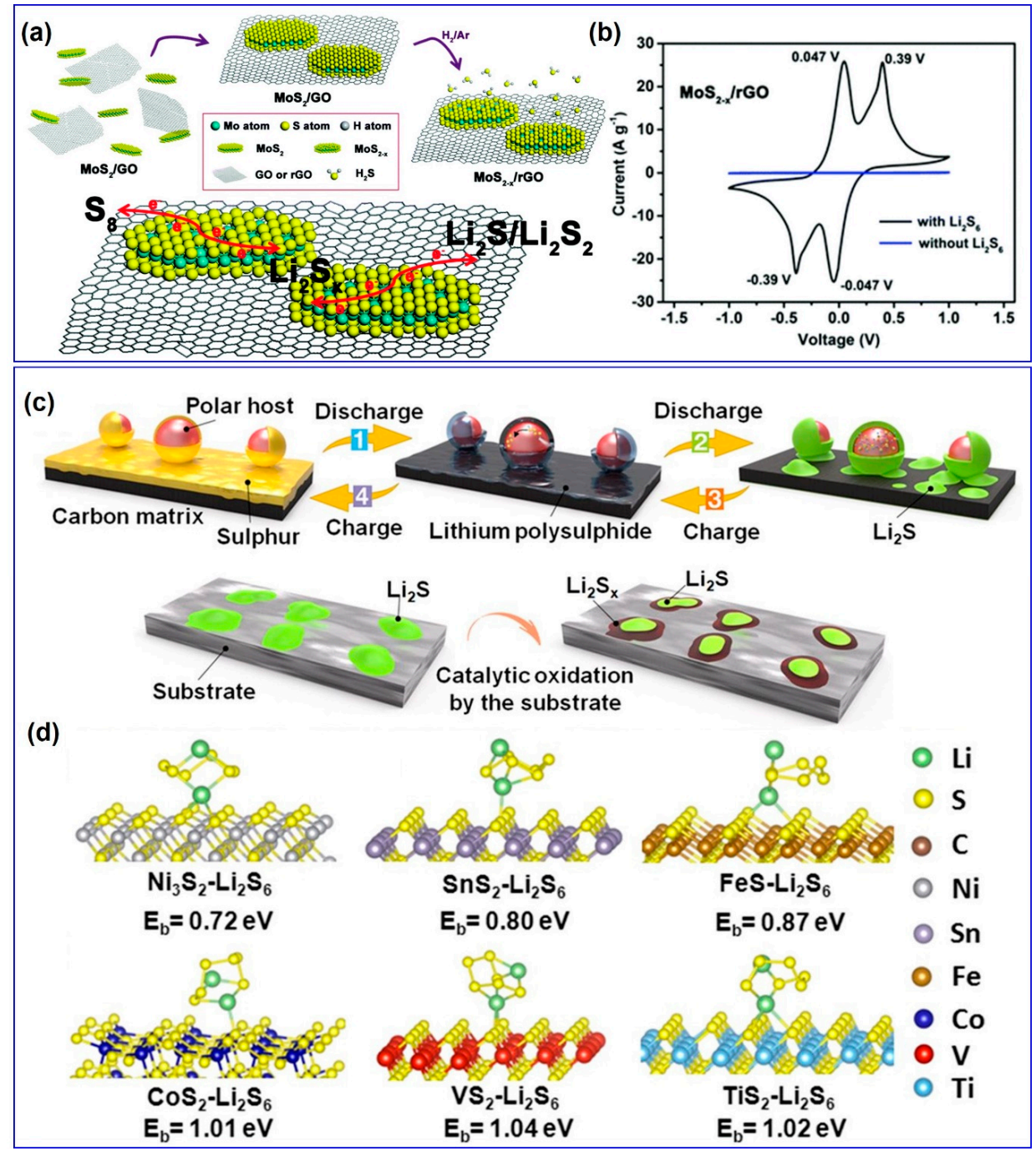

Figure 8. (a) Schematic representation of the $\mathrm{MoS}_{2-\mathrm{x}} / \mathrm{rGO}$ composite and the conversion of $\mathrm{Li}_{2} \mathrm{~S}_{\mathrm{x}}$ on its surface. (b) CVs of the symmetric cells with identical electrodes containing the electrocatalyst $\mathrm{MoS}_{2-\mathrm{x}} / \mathrm{rGO} / \mathrm{S}$. with and without $\mathrm{Li}_{2} \mathrm{~S}_{6}$. Reproduced with permission, Copyright, 2016, Royal Society of Chemistry [104]. (c) Schematic representation of the sulfur conversion process and the $\mathrm{Li}_{2} \mathrm{~S}$ oxidation on the electrocatalytic surface. (d) Atomic conformations, and binding energies for $\mathrm{Li}_{2} \mathrm{~S}_{6}$ species on various metal-sulfide electrocatalytic surfaces. Reproduced with permission, Copyright 2017, National Academy of Sciences [106]. 
Yi Cui and his coworkers have examined various polar transition metal sulfide compounds for LiPS conversion to learn critical parameters in deciphering energy barrier in $\mathrm{Li}_{2} \mathrm{~S}$ oxidation and LiPS adsorption chemistry in Li-S batteries (Figure 8c) [106]. This work demonstrates that the intermetallic conductivity, catalyst, LiPS interaction, fast Li-ion transport, controlled $\mathrm{Li}_{2} \mathrm{~S}$ precipitation, surface-mediated reaction kinetics, and catalytic conversion capability of metal sulfide catalysts are the critical parameters in designing an efficient LiPS conversion catalyst to reduce the overpotential for $\mathrm{Li}_{2} \mathrm{~S}$ decomposition. Further, all of these features are conducive to improve the electrochemical performance of Li-S batteries. Based on a series of investigations by theory combined with experimentation, $\mathrm{TiS}_{2}$, $\mathrm{VS}_{2}$, and $\mathrm{CoS}_{2}$ based compounds have been reported to show excellent binding energy diffusion barriers due to the strong complete interaction between these metal sulfides and the LiPS (Figure 8d). Eventually, the hybrid materials based on $\mathrm{TiS}_{2}, \mathrm{VS}_{2}$, and $\mathrm{CoS}_{2}$ delivered a high capacity of 1008,1093 , and $1033 \mathrm{mAh} \mathrm{g}^{-1}$ at $2 \mathrm{C}$ rate. From the detailed investigation on metal sulfide electrocatalyst, this work provides a basis behind the LiPS conversion catalyst and idea about the rational design of catalyst for LiPS catalytic reactions.

After the successful exploration of metal sulfides for improving the LiPS reaction kinetics, bimetal sulfide compounds have been studied as electrocatalysts for Li-S batteries. Based on the excellent performance of $\mathrm{CoS}_{2}$ and $\mathrm{NiS}_{2}$ in $\mathrm{LiPS}$ conversion, the authors synthesized $\mathrm{NiCO}_{2} \mathrm{~S}_{4}$ using hydrothermal reaction at low temperatures [107]. The as-synthesized material exhibited excellent LiPS adsorption and suppressed LiPS shuttle efficiently due to the strong affinity of bimetal sulfides towards LiPS. More importantly, with the unique architecture of the cathode, the cell exhibited a capacity of $788 \mathrm{mAh} \mathrm{g}^{-1}$ at $0.5 \mathrm{C}$ and low capacity fade of $0.0489 \%$ per cycle at $0.6 \mathrm{C}$ over 1000 cycles. More recently, a flexible binder-free sulfur host composed of $\mathrm{FeCo}_{2} \mathrm{~S}_{4}$ nanotube arrays grown on carbon paper by two-step hydrothermal synthesis was reported [75]. The interconnected carbon skeleton improved the electronic conductivity of the electrode, and the bimetallic sulfides accelerated the electron transfer reaction with reduced LiPS dissolution due to their strong chemical affinity. To evaluate its ability in LiPS conversion, a detailed investigation of $\mathrm{CV}$, charge/discharge, and electrochemical impedance spectroscopy (EIS) studies were carried out and compared with a bare carbon-based electrode. With this improved catalytic effect, the $\mathrm{FeCO}_{2} \mathrm{~S}_{4}$ nanotube array delivers a high specific capacity of $1384 \mathrm{mAh} \mathrm{g}^{-1}$ at $0.1 \mathrm{C}$ rate, and a stable coulombic efficiency of $98 \%$ for 300 cycles was recorded.

\section{Metal Carbide-Sulfide Interactions in Electrocatalysis of LiPS Redox Reactions}

While the poor adsorption properties of hydrophobic carbonaceous cathodes render them inactive towards binding with polar natured LiPS, metal carbide, or more specifically, transition metal carbide (TMCs) based hydrophilic hosts chemically bind with LiPS and facilitate multi-step redox processes in Li-S batteries. The unique electrochemical activity of TMCs stems from the $3 \mathrm{~d}$ electron number of the transition metal atoms and strong interactions between the metals and the electroactive species. Additionally, due to the electron distribution in the carbons, TMCs exhibit unique surface reactivity and catalytic properties close to that of noble metals $[76,108,109]$. Further, MCs comprises of inherent large interlayer channels that are known to shorten the ionic/electronic transport pathways, which assists in the realization of very high power capabilities. In this context, Salem et al. have reported tungsten carbide (WC) and titanium carbide (TiC) based cathodes for Li-S batteries [76]. Initially, spin-polarized DFT calculations were performed to understand the adsorption state of $\mathrm{Li}_{2} \mathrm{~S}_{8}$ on MCs. The results revealed that $\mathrm{Li}_{2} \mathrm{~S}_{8}$ undergoes complete dissociation on $\mathrm{MC}$ upon adsorption while remaining intact over the Gr surface. More importantly, WC (3.56 eV/S atom) and TiC (3.68 eV/S atom) exhibited higher binding energies towards $\mathrm{Li}_{2} \mathrm{~S}_{8}$ due to the polar metal-C bonds compared to $\mathrm{Gr}(0.11 \mathrm{eV} / \mathrm{S}$ atom) and its non-polar C-C bonds. The adsorption capabilities of MCs towards LiPS were further evaluated by UV-Vis spectroscopy, which demonstrated an excellent affinity of $\mathrm{W}$ and Ti edge sites towards adsorption of LiPS. Upon performing electrochemical tests, the TiC electrode unveiled a specific capacity of $1156 \mathrm{mAh} \mathrm{g}^{-1}$ and excellent reversibility. Peng et al. have further investigated the role of conductive polar TiC on liquid-liquid LiPS interconversion and liquid-solid $\left(\mathrm{Li}_{2} \mathrm{~S}\right)$ precipitation 
in comparison with non-polar carbon and semiconducting titanium dioxide surfaces [110]. The authors have predicted that only a polar conductive material can fulfill the requirements for enhancing the interfacial electrochemical kinetics and anchoring LiPS by strong chemical adsorption. Appropriately, first-principle calculations also revealed that binding energies were very high between $\mathrm{Li}_{2} \mathrm{~S}_{4}(-1.89 \mathrm{eV})$ and $\mathrm{Li}_{2} \mathrm{~S}(-2.75 \mathrm{eV})$ on the $\mathrm{TiC}$ surface when compared to the non-polar carbon surface. It was also predicted that improved conductivity can also influence the LiPS interfacial transformations. Further, efforts were directed towards understanding polysulfide redox in liquid phase and $\mathrm{Li}_{2} \mathrm{~S}$ precipitation to provide insights into the correlation between kinetics and electrical conductivity. Given the high conductivity of $\mathrm{TiC}$, it was noted that it exhibited the highest activity towards $\mathrm{Li}_{2} \mathrm{~S}$ precipitation and promoted its growth in the radial direction while impinging in a perpendicular direction. Improved kinetics towards LiPS conversion on the TiC surface, high conductivity, and interactions between LiPS and $\mathrm{TiC}$ has reflected in its excellent capacity of $1032 \mathrm{mAh} \mathrm{g}^{-1}$ and coulombic efficiency of $95 \%$ over 100 cycles.

In an attempt to improve the cycling stability and rate capability of the Li-S battery, Zhou et al. reported a low-cost metal carbide nanoparticles (MCNPs) on carbon nanofibers which can provide both catalytic and adsorption sites on the cathode surface, [77]. DFT models created to understand the nature of chemical interactions predicted strong partial bonding between polar $\mathrm{W}_{2} \mathrm{C}, \mathrm{Mo}_{2} \mathrm{C}, \mathrm{TiC}$, and $\mathrm{LiPS}$ $\left(\mathrm{Li}_{2} \mathrm{~S}_{6}\right)$ with binding energies of $-2.57 \mathrm{eV},-2.71 \mathrm{eV}$, and $-2.32 \mathrm{eV}$, respectively. Thus, these polar MCNPs on the CNF were anticipated to act as anchoring sites for long-chain LiPS making these species electrochemically accessible on the electrode's surface, as shown in Figure 9. Additionally, while the redox of LiPS was found to be triggered upon their adsorption onto the MC surface, the electrocatalytic activity of MCNPs was found to lower the passive overpotentials and enhance the redox kinetics. Overall, a typical Li-S battery assembled with $\mathrm{W}_{2} \mathrm{C}$ NPs-CNFs as the cathode material delivered a high specific capacity of $1200 \mathrm{mAh} \mathrm{g}^{-1}$ at $0.2 \mathrm{C}$ rate with a stable performance of up to 200 cycles.

Further, given that the MCs are layered and puckered sheets of covalently bonded mixed atoms, availability of complete surface area is restrained during their restacking after exfoliation, thus effecting the ions accessibility to the surface. In this context, Bao et al. proposed a flexible delamination and reassembly method for MCs by exploring the highly porous MOF system [111]. For this purpose, they have introduced a metal carbide@ mesoporous carbon hybrid architecture loaded with sulfur $\left(\mathrm{Ti}_{3} \mathrm{C}_{2} \mathrm{~T}_{\mathrm{x}} @\right.$ Meso-C/S). The proposed cathode delivered an initial capacity of $1225.8 \mathrm{mAh} \mathrm{g}^{-1}$ with a high reversible capacity of $704.6 \mathrm{mAh} \mathrm{g}^{-1}$ after 300 cycles. Simultaneously, a control meso-C/S cathode delivered an initial capacity of only $1006.8 \mathrm{mAh} \mathrm{g}^{-1}$, which decreased to $470.2 \mathrm{mAh} \mathrm{g}^{-1}$ after 300 cycles. The evident improvement in the electrochemical performance of the MC was ascribed to the synergetic effect of $\mathrm{Ti}_{3} \mathrm{C}_{2} \mathrm{~T}_{\mathrm{x}}$ nanosheets and the mesoporous structure. It was reported that, during cycling, the active hydrophilic surfaces of exfoliated MC could effectively trap the LiPS, while the mesoporous matrix can arrest the LiPS diffusion and associated shuttle process through strong physical adsorption. In a similar effort, Pourali et al. have demonstrated $\mathrm{Li}_{2} \mathrm{~S} / \mathrm{Ti}_{3} \mathrm{C}_{2} \mathrm{~T}_{\mathrm{x}}$ composite as a cathode material for Li-S batteries [112]. As anticipated, the cells showed superior electrochemical performance, which was attributed to the reduction in energy barrier for $\mathrm{Li}$-ion transport though $\mathrm{Li}_{2} \mathrm{~S}$ particles by the highly conductive $2 \mathrm{D} \mathrm{Ti}_{3} \mathrm{C}_{2} \mathrm{~T}_{\mathrm{x}}$. 


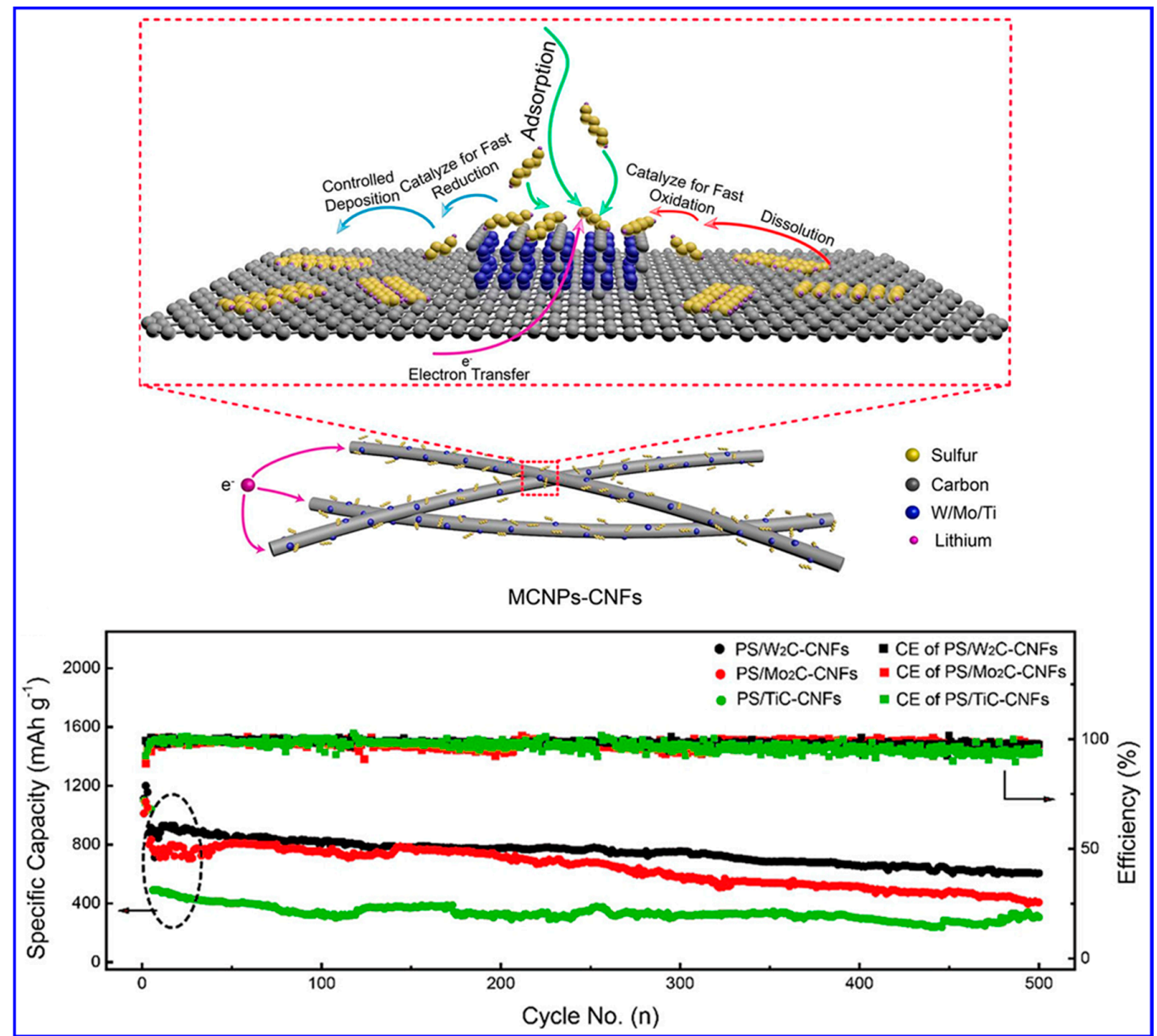

Figure 9. Top: Illustration of MCNPs-CNFs hybrid electrodes functioning; Bottom: comparison of cycling performance of the hybrid electrodes and other control electrodes at $0.2 \mathrm{C}$ rate. Reproduced with permission, Copyright, 2018, American Chemical Society [77]. MCNPs-metal carbide $\left(\mathrm{W}_{2} \mathrm{C}\right)$ nanoparticles; CNFs—carbon nanofibers.

More recently, Luo et al. have introduced boron carbide nanowires ( $\left.\mathrm{B}_{4} \mathrm{C} @ \mathrm{CNF}\right)$ as a bifunctional cathode surface for Li-S batteries (Figure 10a) [101]. The sulfiphilic $\mathrm{B}_{4} \mathrm{C}$ nanowires were found to chemically absorb the LiPS, which were effectively confined in the $\mathrm{B}_{4} \mathrm{C}$ and CNF network. Detailed DFT calculations revealed that the $\mathrm{B}_{4} \mathrm{C}$ exhibits the highest binding energy (3.84 to $12.51 \mathrm{eV}$ ) towards $\mathrm{Li}_{2} \mathrm{~S}_{4}$ in comparison with the non-polar graphite surface $(1.18 \mathrm{eV})$. Further, Bader charge analysis performed to understand the electron charge transfer between $\mathrm{Li}_{2} \mathrm{~S}_{4}$ and $\mathrm{B}_{4} \mathrm{C}$ confirmed the formation of chemical bonds between them, as evidenced by an increase in electron density between $\mathrm{S}$ and surface atoms of $\mathrm{B}_{4} \mathrm{C}$. On the other hand, the inherent catalytic effect of $\mathrm{B}_{4} \mathrm{C}$ was found to be responsible for reducing the overpotentials while facilitating the redox kinetics of LiPS conversion. Additionally, the enhanced LiPS adsorption and subsequent conversion on the free-standing structure can eliminate the need for additional current collector or binders and provide room for increasing the sulfur loading. Based on the CV studies on a Li-S cell, the Li-ion diffusion coefficients were found to be one order higher for the $\mathrm{B}_{4} \mathrm{C} @ \mathrm{CNF}$ electrodes compared to the conventional Li-S cells, further revealing the accelerated redox kinetics on the MC surface. The improved redox chemistry and excellent polysulfide trapping are also reflected in the enhanced long cycling performance. At $1 \mathrm{C}$ rate, the Li-S cells with $\mathrm{B}_{4} \mathrm{C} @ \mathrm{CNF}$ and $\mathrm{CNF}$ delivered an initial capacity of 1024 and $1021 \mathrm{mAh} \mathrm{g}^{-1}$, respectively. But, the cell with CNF displayed a rapid capacity fade over cycling, delivering only $447 \mathrm{mAh} \mathrm{g}^{-1}$ after 500 cycles. On the other hand, $\mathrm{B}_{4} \mathrm{C} @ \mathrm{CNF}$ cell demonstrated and excellent reversibility and cycling stability, delivering $815 \mathrm{mAh} \mathrm{g}^{-1}$ of discharge capacity after 500 cycles. 


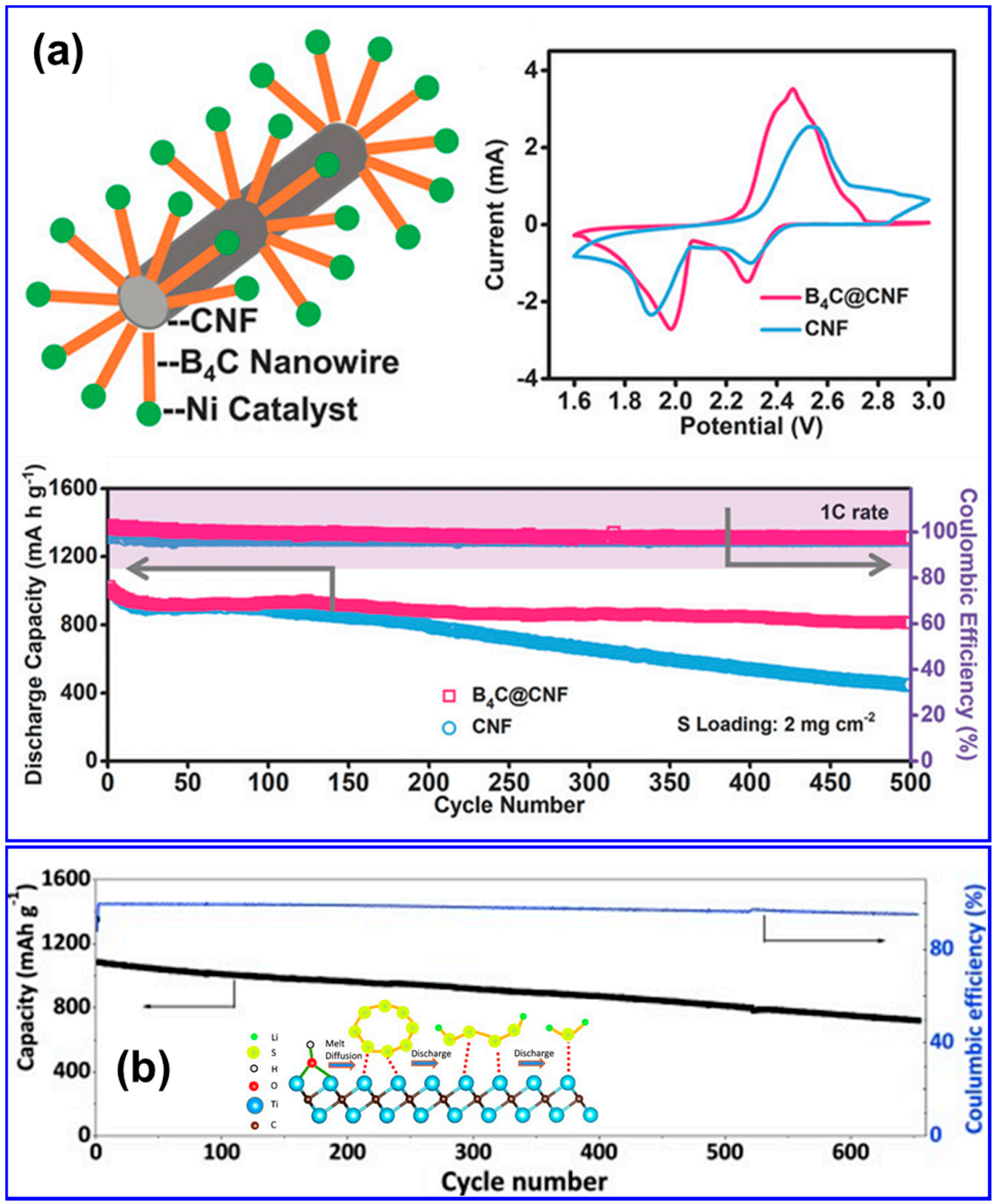

Figure 10. (a) Top left: Schematic structure of the $\mathrm{B}_{4} \mathrm{C} @ \mathrm{CNF}$ electrocatalyst; Top right: CV curves of the electrocatalyst compared with CNF. Bottom: long-term cycling performance of the electrodes. Reproduced with permission, Copyright, 2018, American Chemical Society [101]. (b) Long-term cycling performance of $\mathrm{Ti}_{2} \mathrm{C}$ electrodes at $\mathrm{C} / 2$ rate, inset shows the representative functioning of $\mathrm{Ti}_{2} \mathrm{C}$ depicting the replacement of the Ti-OH bond of the MXene surface with an S-Ti-C bonding on contact with LiPS. Reproduced with permission, Copyright, 2015, Wiley [113].

Another new class of sulfur host materials, the MXenes, has gained much attention in recent times, given their inherently high conductivity and highly active 2D surface with their capability to chemically bond intermediate LiPS through metal-sulfur interactions. Liang et al. have demonstrated an MXene phase $\mathrm{Ti}_{2} \mathrm{C}$ as an effective sulfur host material [113]. As shown in Figure 10b, this material takes advantage of the high 2D electron conductivity of transition metal carbides and the exposed terminal metal sites to bind the LiPS. It was reported that the $\mathrm{Ti}-\mathrm{OH}$ groups in the MXene $\mathrm{Ti}_{2} \mathrm{C}$ nanosheets 
are replaced by Ti-S at elevated temperatures during sulfur infusion. The electronegative $S$ atoms decrease the electron density of Ti atoms, leading to higher binding energy between $\mathrm{Ti}$ and $\mathrm{S}$ compared to the Ti-C bond. Hence, effective anchoring of LiPS was expected on the $\mathrm{Ti}_{2} \mathrm{C}$ surface due to the Lewis acid-base interactions between $\mathrm{Ti}$ and $\mathrm{S}$. Such an anchoring effect resulted in the long cycling performance, where an initial discharge capacity of $1090 \mathrm{mAh} \mathrm{g}^{-1}$ was noted at $0.5 \mathrm{C}$ rate, with just $0.05 \%$ decay per cycle, the cell delivered a capacity of $723 \mathrm{mAh} \mathrm{g}^{-1}$ even after 650 cycles.

While these studies demonstrate the influence of various electrocatalysts on the enhancement of Li-S battery performance, it is equally important to improve the sulfur loading to realize the true potential of the electrocatalysts for real-world applications. In this context, based on the sulfur loading and current rate, Table 3 provides an overview of some contemporary electrocatalysts (metal, metal-oxide, metal-sulfide and metal-carbide) performance in terms of capacity, cycle life, and Coulombic efficiency. This information indicates that exploring heteroatom or new architecture based electrocatalytic materials can help realize high capacities and enable high sulfur loading capabilities.

Table 3. Comparison of sulfur loadings, current rates, and the corresponding capacity, cycle life, coulombic efficiency delivered by the Li-S batteries when various electrocatalytic sulfur hosts are employed.

\begin{tabular}{|c|c|c|c|c|c|c|c|}
\hline & Electrocatalyst & $\begin{array}{l}\text { Sulfur Loading } \\
\quad\left(\mathrm{mg} \mathrm{cm}^{-2}\right)\end{array}$ & C-Rate & $\begin{array}{l}\text { Discharge Capacity } \\
\left(m A h g^{-1}\right)\end{array}$ & Cycles & CE (\%) & Ref. \\
\hline \multirow{10}{*}{ Metals } & \multirow{4}{*}{ Co-Fe-P } & 1 & 0.2 & 1118 & 100 & 100 & \multirow{4}{*}[71]{} \\
\hline & & 1 & 1 & 863 & 500 & 100 & \\
\hline & & 3.7 & 0.2 & $\sim 1100$ & 100 & $\sim 100$ & \\
\hline & & 5.5 & 0.2 & $\sim 890$ & 100 & $\sim 100$ & \\
\hline & \multirow{2}{*}{ Mo nanoclusters } & 1.91 & 1 & $\sim 1100$ & 500 & 99.6 & \multirow{2}{*}[72]{} \\
\hline & & 7.64 & 0.2 & $\sim 800$ & 100 & - & \\
\hline & \multirow{2}{*}{$\begin{array}{l}\text { Co in Nitrogen } \\
\text { doped graphene }\end{array}$} & 2 & 1 & 866 & 500 & $\sim 99.6$ & \multirow{2}{*}{ [114] } \\
\hline & & 6 & 0.2 & $\sim 5.1 \mathrm{mAh} \mathrm{cm}^{-2}$ & 100 & - & \\
\hline & \multirow{2}{*}{ Fe-N-C } & 2.5 & 0.5 & 1631 & 100 & 95 & \multirow{2}{*}{ [115] } \\
\hline & & 5.2 & 3 & 483 & 500 & - & \\
\hline \multirow{4}{*}{$\begin{array}{l}\text { Metal } \\
\text { oxides }\end{array}$} & \multirow{2}{*}{$\mathrm{LiNi}_{0.8} \mathrm{Co}_{0.1} \mathrm{Mn}_{0.1} \mathrm{O}_{2}$} & 0.7 & 0.1 & 1264.3 & 500 & 99.22 & \multirow{2}{*}{ [95] } \\
\hline & & 4.29 & 0.1 & $\sim 700$ & 120 & - & \\
\hline & \multirow{2}{*}{$\mathrm{Co}_{9} \mathrm{~S}_{8}-\mathrm{CoO}$} & 1 & 1 & 956 & 300 & $\sim 100$ & \multirow{2}{*}{ [116] } \\
\hline & & 2.5 & 1 & 925 & 1000 & $\sim 100$ & \\
\hline \multirow{8}{*}{$\begin{array}{l}\text { Metal } \\
\text { sulfides }\end{array}$} & \multirow{3}{*}{$\mathrm{Fe}_{1-\mathrm{x}} \mathrm{S}$} & - & 0.5 & 1070 & 200 & $\sim 100$ & \multirow{3}{*}{ [96] } \\
\hline & & - & 1 & 793 & 200 & - & \\
\hline & & 8.14 & 0.05 & $7.4 \mathrm{mAh} \mathrm{cm}^{-2}$ & 60 & - & \\
\hline & \multirow{2}{*}{$\mathrm{Ni}_{3} \mathrm{~S}_{2}$} & 4 & $1 \mathrm{~mA} \mathrm{~cm}^{-2}$ & 655 & 80 & $\sim 95$ & \multirow{2}{*}{ [97] } \\
\hline & & 4 & $4 \mathrm{~mA} \mathrm{~cm}^{-2}$ & 441 & 150 & - & \\
\hline & \multirow{3}{*}{$\mathrm{MoS}_{2}$} & 1 & 0.2 & 954 & 150 & 99.5 & \multirow{3}{*}{ [117] } \\
\hline & & 1 & 2 & $\sim 750$ & 1000 & $\sim 100$ & \\
\hline & & 3.6 & 0.2 & 714 & 110 & - & \\
\hline \multirow{11}{*}{$\begin{array}{c}\text { Metal } \\
\text { carbides }\end{array}$} & \multirow{4}{*}{$\mathrm{Ti}_{3} \mathrm{C}_{2}$} & $1.2-1.5$ & 0.5 & 1180 & 200 & 99 & \multirow{4}{*}{ [118] } \\
\hline & & $1.2-1.5$ & 1 & 530 & 500 & $\sim 100$ & \\
\hline & & 1 & 1 & 610 & 200 & $\sim 100$ & \\
\hline & & 2.5 & 1 & 475 & 200 & $\sim 100$ & \\
\hline & \multirow{4}{*}{$\mathrm{MoC}_{1-\mathrm{x}}$} & 2 & $800 \mathrm{~mA} \mathrm{~g}^{-1}$ & 1000 & 500 & $\sim 98$ & \multirow{4}{*}{ [119] } \\
\hline & & 2 & $1600 \mathrm{~mA} \mathrm{~g}^{-1}$ & 900 & 200 & - & \\
\hline & & 4 & $1.6 \mathrm{~mA} \mathrm{~cm}-2$ & $2.6 \mathrm{mAh} \mathrm{cm}^{-2}$ & 100 & 88 & \\
\hline & & 6 & $1.6 \mathrm{~mA} \mathrm{~cm}^{-2}$ & $3.6 \mathrm{mAh} \mathrm{cm}^{-2}$ & 100 & 91 & \\
\hline & \multirow{3}{*}{$\mathrm{Mo}_{2} \mathrm{C}$} & $1.5-1.8$ & 0.5 & 1206 & 100 & $\sim 100$ & \multirow{3}{*}{ [120] } \\
\hline & & $1.5-1.8$ & 2 & 802 & 900 & $\sim 100$ & \\
\hline & & 2.5 & 1 & 835 & 100 & $\sim 100$ & \\
\hline
\end{tabular}

\section{Summary and Outlook}

Controlling the liquid LiPS dissolution and subsequent shuttling phenomenon while ensuring high rate capability embraces the significance to realize high theoretical energy lithium-sulfur (Li-S) batteries with long cycle life. Towards this goal, it is highly desired to design a cathode architecture 
that has the simultaneous capability to trap the liquid LiPS while accelerating their conversion reaction kinetics during charge/discharge. This review provides an overview of the contemporary efforts made to capture the liquid LiPS and expedite the subsequent conversion reactions through various chemical anchoring strategies exhibited by several cathode surfaces. Metal nanoparticles dispersed in highly porous architecture and their interactions with LiPS during charge/discharge provides plenty of active sites for confining the LiPS, which helps realize a high sulfur loading. Additionally, the proven metal-sulfide interaction during the LiPS redox reaction not only reduces the LiPS shuttling phenomenon but also improves the reversibility of the electronically insulating end products on the cathode surface along with an enhanced active materials utilization. A combination of electronic conductivity and surface polarity in metal oxide-based host materials provides a bifunctional activity to the sulfur cathodes, which significantly mitigates the LiPS dissolution. Besides, this surface-enhanced redox catalysis of LiPS allows spatially controlled $\mathrm{Li}_{2} \mathrm{~S}$ precipitation and forms an effective interface that significantly lowers the polarization potential during the charging process and improves the utilization of the active material. In search of a cost-effective and efficient catalyst for Li-S batteries, these bifunctional oxide type host materials are a promising approach towards high capacity and long cycle life Li-S batteries.

Inspired by the industrial hydrodesulfurization catalytic process with sulfiphilic functional groups, strong LiPS adsorption followed by their conversion is effectively enabled through sulfide-based metallic compounds. In contrast to oxides, sulfiphilic interactions creates a stronger affinity between metal sulfides and LiPS, thus ensuring their redox conversion process at a confined location along with inherent catalytic functions. This approach demonstrates that the mechanism involved in surface interaction holds a significant role in controlling the LiPS dissolution and associated shuttling issues. The advantages of employing this class of catalytic approach in $\mathrm{Li}-\mathrm{S}$ batteries include (i) retention of the low-cost advantage of Li-S batteries by the economically viable metal sulfides; (ii) the possibility to tune the electrocatalytic activity of metal sulfide surface by adjusting the number of their active sites (iii) feasibility for scaling up the synthesis of such structures, making this approach easily adaptable for practical applications. Further, a synergetic effect between the hydrophilic nature and high electrochemical activity from the $3 \mathrm{~d}$ electron number in transition metals renders metal carbides a unique capability to adsorb LiPS. More importantly, these metal carbides present themselves as effective and economically viable electrocatalysts for Li-S batteries, given the inherent catalytic activity of metal.

Though existing strategies effectively direct researchers to select appropriate cathode hosts for sulfur, several challenges remain for practical Li-S purposes. Further enhancement of the electrocatalysis concept in Li-S batteries requires consideration of the following factors:

(i) As the intermediate LiPS forms with different chain lengths during the reactions and undergoes manifold (electro) chemical transformations, their binding strength varies from surface to surface. In such circumstances, the cathode surfaces no longer can offer a ubiquitous anchoring effect towards all the intermediate LiPS, and subsequently, some tend to undergo dissolution. Exploring the design principle for anchoring of LiPS on the cathode substrates that are capable of adsorbing all the intermediate LiPS while catalyzing the subsequent redox reactions is imperative to completely restrain the PS shuttle.

(ii) The catalysts with high surface area and exceptional electronic conductivity need to be developed to promote $\mathrm{Li}^{+}$transportation in the inner parts of cathodes to access the active materials while facilitating the redox conversion reaction. This could provide an opportunity to achieve high sulfur loading with low electrolyte/sulfur ratio to realize high energy density Li-S batteries. Besides, maximizing the sulfur loading without compromising on the electrocatalytic activity holds the key to realize the effective utilization of the electrocatalysts and, ultimately, high energy density Li-S batteries. Additionally, catalytic cathodes should have a rigid structure with enough porosity to enable uniform distribution of active materials and accommodate volume changes during charge/discharge. 
(iii) An in-depth understanding of the phenomenon occurring at the electrode/electrolyte interface with theoretical and sophisticated in situ measurements is vital to understand the interactions of LiPS with the catalytic cathodes in real-time. This could reveal essential information such as the nature of such interactions, LiPS reaction pathways on catalyst cathodes during the entire reactions, etc., which are essential to elucidate the accelerated reversible redox pathways of sulfur redox reactions.

Furthermore, the target application of the Li-S batteries, which include pouch-cells with high sulfur loading to deliver high energy density and battery packs for electric vehicles, surges the demand for the metallic lithium (Li) [121]. In this context, the current global Li resource was estimated to be around 39 million tones (Mt) [122]. It is estimated that Li consumption by the battery industry accounts for around $35 \%$ of the total Li usage, which is expected to grow to $66 \%$ by 2024 [123]. More precisely, demand for Li metal drastically increased over the years, with the requirement being 85 metric tons in 2018 while it was only 39.3 metric tons in 2016. Interestingly, the price of $\mathrm{Li}$ (per $\mathrm{kWh}$ ) has been decreasing over the past few decades, for instance, a $30 \mathrm{kWh}$ lithium-ion battery (LIB) cost over $€ 7500$ in 2007, which reduced to $€ 800,200$ in 2010 and 2018 respectively, and is expected to drop to $€ 100$ by 2025 [124]. Even with the current rapid rate of development in the battery industry, the global Li resources are estimated to suffice the current and near-future needs, with the highest requirement for the 2010 to 2100 period not exceeding $20 \mathrm{Mt} \mathrm{[122].} \mathrm{However,} \mathrm{despite} \mathrm{their} \mathrm{appealing} \mathrm{advantages,}$ LIBs are still expensive, and their short lifetime ( $<3$ years) poses several ecological and humanitarian concerns due to the generation of massive wastes $[125,126]$. Hence, it would be beneficial to accelerate and explore the battery recycling methodologies, to not only reduce the pileup of hazardous battery components but also to support their supply chain and alleviate the depletion of natural resources towards a sustainable future.

In summary, electrocatalysis of LiPS redox reactions in Li-S batteries is a practical approach to mitigate the shuttling phenomenon and electronic conductivity issues during the charge/discharge processes. With the current advancement in the theoretical and experimental understanding and designing strategies, they are expected to guide the development of sophisticated catalytic surfaces and pave new pathways leading to the high performance and long cycle life Li-S batteries for commercial purposes.

Author Contributions: Conceptualization, K.M., N.K.T. and L.M.R.A.; investigation, K.M., S.N., N.K.T.; writing —original draft preparation, K.M., S.N., N.K.T.; writing—supporting, S.R., M.Y.; writing—review and editing, K.M., N.K.T., M.Y. and L.M.R.A.; supervision, N.K.T., L.M.R.A.; funding acquisition, L.M.R.A. All authors have read and agreed to the published version of the manuscript.

Funding: This material is based on work supported by the National Science Foundation under Grant No. 1751472.

Conflicts of Interest: The authors declare no conflict of interest.

\section{References}

1. Bruce, P.G.; Freunberger, S.A.; Hardwick, L.J.; Tarascon, J.M. Li- $\mathrm{O}_{2}$ and Li-S batteries with high energy storage. Nat. Mater. 2012, 11, 19-29. [CrossRef] [PubMed]

2. Armand, M.; Tarascon, J.M. Building better batteries. Nature 2008, 451, 652-657. [CrossRef] [PubMed]

3. Miroshnikov, M.; Kato, K.; Babu, G.; Kumar, N.; Mahankali, K.; Hohenstein, E.; Wang, H.; Satapathy, S.; Divya, K.P.; Asare, H.; et al. Nature-Derived Sodium-Ion Battery: Mechanistic Insights into Na-Ion Coordination within Sustainable Molecular Cathode Materials. ACS Appl. Energy Mater. 2019, 2, 8596-8604. [CrossRef]

4. Miroshnikov, M.; Mahankali, K.; Thangavel, N.K.; Satapathy, S.; Arava, L.M.R.; Ajayan, P.M.; John, G. Bioderived Molecular Electrodes for Next-Generation Energy-Storage Materials. ChemSusChem 2020, 13, 2186-2204. [CrossRef]

5. Manthiram, A.; Fu, Y.; Chung, S.H.; Zu, C.; Su, Y.S. Rechargeable lithium-sulfur batteries. Chem. Rev. 2014, 114, 11751-11787. [CrossRef] 
6. Li, Z.; Huang, Y.M.; Yuan, L.X.; Hao, Z.X.; Huang, Y.H. Status and prospects in sulfur-carbon composites as cathode materials for rechargeable lithium-sulfur batteries. Carbon 2015, 92, 41-63. [CrossRef]

7. Barchasz, C.; Leprêtre, J.C.; Alloin, F.; Patoux, S. New insights into the limiting parameters of the Li/S rechargeable cell. J. Power Sources 2012, 199, 322-330. [CrossRef]

8. Jung, Y.; Kim, S. New approaches to improve cycle life characteristics of lithium-sulfur cells. Electrochem. Commun. 2007, 9, 249-254. [CrossRef]

9. Barghamadi, M.; Kapoor, A.; Wen, C. A review on Li-S batteries as a high efficiency rechargeable lithium battery. J. Electrochem. Soc. 2013, 160, A1256-A1263. [CrossRef]

10. Ji, X.; Lee, K.T.; Nazar, L.F. A highly ordered nanostructured carbon-sulphur cathode for lithium-sulphur batteries. Nat. Mater. 2009, 8, 500-506. [CrossRef]

11. Angulakshmi, N.; Stephan, A.M. Efficient electrolytes for lithium-sulfur batteries. Front. Energy Res. 2015, 3, 17. [CrossRef]

12. Mikhaylik, Y.V.; Akridge, J.R. Polysulfide shuttle study in the Li/S battery system. J. Electrochem. Soc. 2004, 151, A1969-A1976. [CrossRef]

13. Mahankali, K.; Thangavel, N.K.; Gopchenko, D.; Arava, L.M.R. Atomically Engineered Transition Metal Dichalcogenides for Liquid Polysulfide Adsorption and Their Effective Conversion in Li-S Batteries. ACS Appl. Mater. Interfaces 2020, 12, 27112-27121. [CrossRef] [PubMed]

14. Cheon, S.E.; Ko, K.S.; Cho, J.H.; Kim, S.W.; Chin, E.Y.; Kim, H.T. Rechargeable lithium sulfur battery I. Structural change of sulfur cathode during discharge and charge. J. Electrochem. Soc. 2003, 150, A796-A799. [CrossRef]

15. Mahankali, K.; Thangavel, N.K.; Reddy Arava, L.M. In Situ Electrochemical Mapping of Lithium-Sulfur Battery Interfaces Using AFM-SECM. Nano Lett. 2019, 19, 5229-5236. [CrossRef]

16. Luo, Y.; Guo, L.; Xiao, M.; Wang, S.; Ren, S.; Han, D.; Meng, Y. Strategies for inhibiting anode dendrite growth in lithium-sulfur batteries. J. Mater. Chem. A 2020, 8, 4629-4646. [CrossRef]

17. Xu, X.; Wang, S.; Wang, H.; Xu, B.; Hu, C.; Jin, Y.; Liu, J.; Yan, H. The suppression of lithium dendrite growth in lithium sulfur batteries: A review. J. Energy Storage 2017, 13, 387-400. [CrossRef]

18. Xie, K.; Yuan, K.; Zhang, K.; Shen, C.; Lv, W.; Liu, X.; Wang, J.G.; Wei, B. Dual Functionalities of Carbon Nanotube Films for Dendrite-Free and High Energy-High Power Lithium-Sulfur Batteries. ACS Appl. Mater. Interfaces 2017, 9, 4605-4613. [CrossRef]

19. Chen, L.; Shaw, L.L. Recent advances in lithium-sulfur batteries. J. Power Sources 2014, 267, 770-783. [CrossRef]

20. Choi, Y.J.; Chung, Y.D.; Baek, C.Y.; Kim, K.W.; Ahn, H.J.; Ahn, J.H. Effects of carbon coating on the electrochemical properties of sulfur cathode for lithium/sulfur cell. J. Power Sources 2008, 184, 548-552. [CrossRef]

21. Zhang, B.; Lai, C.; Zhou, Z.; Gao, X. Preparation and electrochemical properties of sulfur-acetylene black composites as cathode materials. Electrochim. Acta 2009, 54, 3708-3713. [CrossRef]

22. Liang, C.; Dudney, N.J.; Howe, J.Y. Hierarchically structured sulfur/carbon nanocomposite material for high-energy lithium battery. Chem. Mater. 2009, 21, 4724-4730. [CrossRef]

23. Guo, J.; Xu, Y.; Wang, C. Sulfur-impregnated disordered carbon nanotubes cathode for lithium-sulfur batteries. Nano Lett. 2011, 11, 4288-4294. [CrossRef] [PubMed]

24. Yuan, L.; Yuan, H.; Qiu, X.; Chen, L.; Zhu, W. Improvement of cycle property of sulfur-coated multi-walled carbon nanotubes composite cathode for lithium/sulfur batteries. J. Power Sources 2009, 189, 1141-1146. [CrossRef]

25. He, G.; Evers, S.; Liang, X.; Cuisinier, M.; Garsuch, A.; Nazar, L.F. Tailoring porosity in carbon nanospheres for lithium-sulfur battery cathodes. ACS Nano 2013, 7, 10920-10930. [CrossRef] [PubMed]

26. Ji, L.; Rao, M.; Zheng, H.; Zhang, L.; Li, Y.; Duan, W.; Guo, J.; Cairns, E.J.; Zhang, Y. Graphene oxide as a sulfur immobilizer in high performance lithium/sulfur cells. J. Am. Chem. Soc. 2011, 133, 18522-18525. [CrossRef]

27. Babu, G.; Arava, L.M.R. Graphene-decorated graphite-sulfur composite as a high-tap-density electrode for Li-S batteries. RSC Adv. 2015, 5, 47621-47627. [CrossRef]

28. Park, M.S.; Yu, J.S.; Kim, K.J.; Jeong, G.; Kim, J.H.; Yim, T.; Jo, Y.N.; Hwang, U.; Kang, S.; Woo, T. Porous carbon spheres as a functional conducting framework for use in lithium-sulfur batteries. RSC Adv. 2013, 3, 11774-11781. [CrossRef] 
29. Liu, X.; Huang, J.Q.; Zhang, Q.; Mai, L. Nanostructured Metal Oxides and Sulfides for Lithium-Sulfur Batteries. Adv. Mater. 2017, 29, 1601759. [CrossRef]

30. He, J.; Manthiram, A. A review on the status and challenges of electrocatalysts in lithium-sulfur batteries. Energy Storage Mater. 2019, 20, 55-70. [CrossRef]

31. Song, M.S.; Han, S.C.; Kim, H.S.; Kim, J.H.; Kim, K.T.; Kang, Y.M.; Ahn, H.J.; Dou, S.; Lee, J.Y. Effects of nanosized adsorbing material on electrochemical properties of sulfur cathodes for $\mathrm{Li} / \mathrm{S}$ secondary batteries. J. Electrochem. Soc. 2004, 151, A791-A795. [CrossRef]

32. Choi, Y.; Jung, B.; Lee, D.; Jeong, J.; Kim, K.; Ahn, H.; Cho, K.; Gu, H. Electrochemical properties of sulfur electrode containing nano $\mathrm{Al}_{2} \mathrm{O}_{3}$ for lithium/sulfur cell. Phys. Scr. 2007, 2007, 62. [CrossRef]

33. Pang, Q.; Kundu, D.; Cuisinier, M.; Nazar, L.F. Surface-enhanced redox chemistry of polysulphides on a metallic and polar host for lithium-sulphur batteries. Nat. Commun. 2014, 5, 4759. [CrossRef] [PubMed]

34. Ponraj, R.; Kannan, A.G.; Ahn, J.H.; Kim, D.-W. Improvement of cycling performance of lithium-sulfur batteries by using magnesium oxide as a functional additive for trapping lithium polysulfide. ACS Appl. Mater. Interfaces 2016, 8, 4000-4006. [CrossRef]

35. Cao, B.; Li, D.; Hou, B.; Mo, Y.; Yin, L.; Chen, Y. Synthesis of double-shell $\mathrm{SnO}_{2} @ \mathrm{C}$ hollow nanospheres as sulfur/sulfide cages for lithium-sulfur batteries. ACS Appl. Mater. Interfaces 2016, 8, 27795-27802. [CrossRef]

36. Kong, Y.; Luo, J.; Jin, C.; Yuan, H.; Sheng, O.; Zhang, L.; Fang, C.; Zhang, W.; Huang, H.; Xia, Y. Enhanced sulfide chemisorption by conductive Al-doped $\mathrm{ZnO}$ decorated carbon nanoflakes for advanced Li-S batteries. Nano Res. 2018, 11, 477-489. [CrossRef]

37. Rehman, S.; Guo, S.; Hou, Y. Rational Design of $\mathrm{Si} / \mathrm{SiO}_{2} @$ Hierarchical Porous Carbon Spheres as Efficient Polysulfide Reservoirs for High-Performance Li-S Battery. Adv. Mater. 2016, 28, 3167-3172. [CrossRef]

38. Liang, Z.; Zheng, G.; Li, W.; Seh, Z.W.; Yao, H.; Yan, K.; Kong, D.; Cui, Y. Sulfur cathodes with hydrogen reduced titanium dioxide inverse opal structure. ACS Nano 2014, 8, 5249-5256. [CrossRef]

39. Cao, J.; Chen, C.; Zhao, Q.; Zhang, N.; Lu, Q.; Wang, X.; Niu, Z.; Chen, J. A Flexible Nanostructured Paper of a Reduced Graphene Oxide-Sulfur Composite for High-Performance Lithium-Sulfur Batteries with Unconventional Configurations. Adv. Mater. 2016, 28, 9629-9636. [CrossRef]

40. Ma, G.; Wen, Z.; Jin, J.; Lu, Y.; Wu, X.; Wu, M.; Chen, C. Hollow polyaniline sphere@ sulfur composites for prolonged cycling stability of lithium-sulfur batteries. J. Mater. Chem. A 2014, 2, 10350-10354. [CrossRef]

41. Ma, G.; Wen, Z.; Jin, J.; Lu, Y.; Wu, X.; Liu, C.; Chen, C. Enhancement of long stability of Li-S battery by thin wall hollow spherical structured polypyrrole based sulfur cathode. RSC Adv. 2014, 4, 21612-21618. [CrossRef]

42. Yang, T.; Wang, X.; Wang, D.; Li, S.; Xie, D.; Zhang, X.; Xia, X.; Tu, J. Facile and scalable synthesis of nanosized core-shell $\mathrm{Li}_{2} \mathrm{~S} @ \mathrm{C}$ composite for high-performance lithium-sulfur batteries. J. Mater. Chem. A 2016, 4, 16653-16660. [CrossRef]

43. Yu, R.; Chung, S.-H.; Chen, C.-H.; Manthiram, A. A core-shell cathode substrate for developing high-loading, high-performance lithium-sulfur batteries. J. Mater. Chem. A 2018, 6, 24841-24847. [CrossRef]

44. Li, L.; Hou, L.; Cheng, J.; Simmons, T.; Zhang, F.; Zhang, L.T.; Linhardt, R.J.; Koratkar, N. A flexible carbon/sulfur-cellulose core-shell structure for advanced lithium-sulfur batteries. Energy Storage Mater. 2018, 15, 388-395. [CrossRef]

45. Bucur, C.B.; Muldoon, J.; Lita, A. A layer-by-layer supramolecular structure for a sulfur cathode. Energy Environ. Sci. 2016, 9, 992-998. [CrossRef]

46. Seh, Z.W.; Li, W.; Cha, J.J.; Zheng, G.; Yang, Y.; McDowell, M.T.; Hsu, P.C.; Cui, Y. Sulphur-TiO 2 yolk-shell nanoarchitecture with internal void space for long-cycle lithium-sulphur batteries. Nat. Commun. 2013, 4, $1-6$.

47. Zhou, W.; Yu, Y.; Chen, H.; DiSalvo, F.J.; Abruna, H.D. Yolk-shell structure of polyaniline-coated sulfur for lithium-sulfur batteries. J. Am. Chem. Soc. 2013, 135, 16736-16743. [CrossRef] [PubMed]

48. Pei, F.; Lin, L.; Ou, D.; Zheng, Z.; Mo, S.; Fang, X.; Zheng, N. Self-supporting sulfur cathodes enabled by two-dimensional carbon yolk-shell nanosheets for high-energy-density lithium-sulfur batteries. Nat. Commun. 2017, 8, 482. [CrossRef]

49. Liang, X.; Nazar, L.F. In Situ Reactive Assembly of Scalable Core-Shell Sulfur- $\mathrm{MnO}_{2}$ Composite Cathodes. ACS Nano 2016, 10, 4192-4198. [CrossRef]

50. Evers, S.; Yim, T.; Nazar, L.F. Understanding the nature of absorption/adsorption in nanoporous polysulfide sorbents for the Li-S battery. J. Phys. Chem. C 2012, 116, 19653-19658. [CrossRef] 
51. Gopalakrishnan, D.; Lee, A.; Thangavel, N.K.; Arava, L.M.R. Facile synthesis of electrocatalytically active NbS 2 nanoflakes for an enhanced hydrogen evolution reaction (HER). Sustain. Energy Fuels 2018, 2, $96-102$. [CrossRef]

52. Kumar, T.N.; Chandrasekaran, N.; Phani, K.L. Structural and electronic modification of $\mathrm{MoS}_{2}$ nanosheets using S-doped carbon for efficient electrocatalysis of the hydrogen evolution reaction. Chem. Commun. 2015, 51, 5052-5055. [CrossRef] [PubMed]

53. Yu, Y.; Gao, Y.; Hu, K.; Blanchard, P.Y.; Noël, J.M.; Nareshkumar, T.; Phani, K.L.; Friedman, G.; Gogotsi, Y.; Mirkin, M.V. Electrochemistry and electrocatalysis at single gold nanoparticles attached to carbon nanoelectrodes. ChemElectroChem 2015, 2, 58-63. [CrossRef]

54. Kumar, T.N.; Sivabalan, S.; Chandrasekaran, N.; Phani, K.L. Synergism between polyurethane and polydopamine in the synthesis of Ni-Fe alloy monoliths. Chem. Commun. 2015, 51, 1922-1925. [CrossRef] [PubMed]

55. Stephens, I.E.; Ducati, C.; Fray, D.J. Correlating microstructure and activity for polysulfide reduction and oxidation at $\mathrm{WS}_{2}$ electrocatalysts. J. Electrochem. Soc. 2013, 160, A757-A768. [CrossRef]

56. Munaiah, Y.; Suresh, S.; Dheenadayalan, S.; Pillai, V.K.; Ragupathy, P. Comparative Electrocatalytic performance of single-walled and multiwalled carbon nanotubes for zinc bromine redox flow batteries. J. Phys. Chem. C 2014, 118, 14795-14804. [CrossRef]

57. Munaiah, Y.; Dheenadayalan, S.; Ragupathy, P.; Pillai, V.K. High performance carbon nanotube based electrodes for zinc bromine redox flow batteries. ECS J. Solid State Sci. Technol. 2013, 2, M3182. [CrossRef]

58. Munaiah, Y.; Ragupathy, P.; Pillai, V.K. Single-step synthesis of halogenated graphene through electrochemical exfoliation and its utilization as electrodes for zinc bromine redox flow battery. J. Electrochem. Soc. 2016, 163, A2899-A2910. [CrossRef]

59. Yuan, Z.; Peng, H.J.; Hou, T.Z.; Huang, J.Q.; Chen, C.M.; Wang, D.W.; Cheng, X.B.; Wei, F.; Zhang, Q. Powering lithium-sulfur battery performance by propelling polysulfide redox at sulfiphilic hosts. Nano Lett. 2016, 16, 519-527. [CrossRef]

60. Babu, G.; Ababtain, K.; Ng, K.S.; Arava, L.M.R. Electrocatalysis of lithium polysulfides: Current collectors as electrodes in Li/S battery configuration. Sci. Rep. 2015, 5, 8763. [CrossRef]

61. Al Salem, H.; Babu, G.; Rao, C.V.; Arava, L.M. Electrocatalytic Polysulfide Traps for Controlling Redox Shuttle Process of Li-S Batteries. J. Am. Chem. Soc. 2015, 137, 11542-11545. [CrossRef] [PubMed]

62. Babu, G.; Masurkar, N.; Al Salem, H.; Arava, L.M. Transition Metal Dichalcogenide Atomic Layers for Lithium Polysulfides Electrocatalysis. J. Am. Chem. Soc. 2017, 139, 171-178. [CrossRef] [PubMed]

63. Jain, A.; Ong, S.P.; Hautier, G.; Chen, W.; Richards, W.D.; Dacek, S.; Cholia, S.; Gunter, D.; Skinner, D.; Ceder, G. Commentary: The Materials Project: A materials genome approach to accelerating materials innovation. APL Mater. 2013, 1, 011002. [CrossRef]

64. Ong, S.P.; Richards, W.D.; Jain, A.; Hautier, G.; Kocher, M.; Cholia, S.; Gunter, D.; Chevrier, V.L.; Persson, K.A.; Ceder, G. Python Materials Genomics (pymatgen): A robust, open-source python library for materials analysis. Comput. Mater. Sci. 2013, 68, 314-319. [CrossRef]

65. Momma, K.; Izumi, F. VESTA 3 for three-dimensional visualization of crystal, volumetric and morphology data. J. Appl. Cryst. 2011, 44, 1272-1276. [CrossRef]

66. Reddy, A.; Shaijumon, M.; Rajalakshmi, N.; Ramaprabhu, S. Performance of proton exchange membrane fuel cells using Pt/MWNT-Pt/C composites as electrocatalysts for oxygen reduction reaction in proton exchange membrane fuel cells. J. Fuel Cell Sci. Technol. 2010, 7, 021001. [CrossRef]

67. Mosavati, N.; Chitturi, V.R.; Arava, L.M.R.; Salley, S.O.; Ng, K.S. Effects of Nickel Particle Size and Graphene Support on the Electrochemical Performance of Lithium/Dissolved Polysulfide Batteries. Electrochim. Acta 2015, 185, 297-303. [CrossRef]

68. Thangavel, N.K.; Gopalakrishnan, D.; Arava, L.M.R. Understanding Heterogeneous Electrocatalysis of Lithium Polysulfide Redox on Pt and $\mathrm{WS}_{2}$ Surfaces. J. Phys. Chem. C 2017, 121, 12718-12725. [CrossRef]

69. Fan, C.Y.; Xiao, P.; Li, H.H.; Wang, H.F.; Zhang, L.L.; Sun, H.Z.; Wu, X.L.; Xie, H.M.; Zhang, J.P. Nanoscale Polysulfides Reactors Achieved by Chemical Au-S Interaction: Improving the Performance of Li-S Batteries on the Electrode Level. ACS Appl. Mater. Interfaces 2015, 7, 27959-27967. [CrossRef]

70. Sawas, A.; Babu, G.; Thangavel, N.K.; Arava, L.M.R. Electrocatalysis driven high energy density Li-ion polysulfide battery. Electrochim. Acta 2019, 307, 253-259. [CrossRef] 
71. Chen, Y.; Zhang, W.; Zhou, D.; Tian, H.; Su, D.; Wang, C.; Stockdale, D.; Kang, F.; Li, B.; Wang, G. Co-Fe Mixed Metal Phosphide Nanocubes with Highly Interconnected-Pore Architecture as an Efficient Polysulfide Mediator for Lithium-Sulfur Batteries. ACS Nano 2019, 13, 4731-4741. [CrossRef] [PubMed]

72. Li, Y.; Wang, C.; Wang, W.; Eng, A.Y.S.; Wan, M.; Fu, L.; Mao, E.; Li, G.; Tang, J.; Seh, Z.W. Enhanced Chemical Immobilization and Catalytic Conversion of Polysulfide Intermediates Using Metallic Mo Nanoclusters for High-Performance Li-S Batteries. ACS Nano 2019, 14, 1148-1157. [CrossRef] [PubMed]

73. Zheng, C.; Niu, S.; Lv, W.; Zhou, G.; Li, J.; Fan, S.; Deng, Y.; Pan, Z.; Li, B.; Kang, F. Propelling polysulfides transformation for high-rate and long-life lithium-sulfur batteries. Nano Energy 2017, 33, 306-312. [CrossRef]

74. Ma, L.; Chen, R.; Zhu, G.; Hu, Y.; Wang, Y.; Chen, T.; Liu, J.; Jin, Z. Cerium oxide nanocrystal embedded bimodal micromesoporous nitrogen-rich carbon nanospheres as effective sulfur host for lithium-sulfur batteries. ACS Nano 2017, 11, 7274-7283. [CrossRef]

75. Guo, B.; Bandaru, S.; Dai, C.; Chen, H.; Zhang, Y.; Xu, Q.; Bao, S.; Chen, M.; Xu, M. Self-Supported FeCo $\mathrm{C}_{4}$ Nanotube Arrays as Binder-Free Cathodes for Lithium-Sulfur Batteries. ACS Appl. Mater. Interfaces 2018, 10, 43707-43715. [CrossRef]

76. Al Salem, H.; Chitturi, V.R.; Babu, G.; Santana, J.A.; Gopalakrishnan, D.; Arava, L.M.R. Stabilizing polysulfide-shuttle in a Li-S battery using transition metal carbide nanostructures. RSC Adv. 2016, 6, 110301-110306. [CrossRef]

77. Zhou, F.; Li, Z.; Luo, X.; Wu, T.; Jiang, B.; Lu, L.L.; Yao, H.B.; Antonietti, M.; Yu, S.H. Low cost metal carbide nanocrystals as binding and electrocatalytic sites for high performance Li-S batteries. Nano Lett. 2018, 18, 1035-1043. [CrossRef] [PubMed]

78. Ghosh, A.; Garapati, M.S.; Vijaya Kumar Saroja, A.P.; Sundara, R. Polar Bilayer Cathode for Advanced Lithium-Sulfur Battery: Synergy Between Polysulfide Conversion and Confinement. J. Phys. Chem. C 2019, 123, 10777-10787. [CrossRef]

79. Liang, X.; Hart, C.; Pang, Q.; Garsuch, A.; Weiss, T.; Nazar, L.F. A highly efficient polysulfide mediator for lithium-sulfur batteries. Nat. Commun. 2015, 6, 5682. [CrossRef] [PubMed]

80. Imtiaz, S.; Ali Zafar, Z.; Razaq, R.; Sun, D.; Xin, Y.; Li, Q.; Zhang, Z.; Zheng, L.; Huang, Y.; Anderson, J.A. Electrocatalysis on Separator Modified by Molybdenum Trioxide Nanobelts for Lithium-Sulfur Batteries. Adv. Mater. Interfaces 2018, 5, 1800243. [CrossRef]

81. Lin, H.; Zhang, S.; Zhang, T.; Ye, H.; Yao, Q.; Zheng, G.W.; Lee, J.Y. Elucidating the Catalytic Activity of Oxygen Deficiency in the Polysulfide Conversion Reactions of Lithium-Sulfur Batteries. Adv. Energy Mater. 2018, 8, 1801868. [CrossRef]

82. Guo, Y.; Zhang, Y.; Zhang, Y.; Xiang, M.; Wu, H.; Liu, H.; Dou, S. Interwoven $\mathrm{V}_{2} \mathrm{O}_{5}$ nanowire/graphene nanoscroll hybrid assembled as efficient polysulfide-trapping-conversion interlayer for long-life lithium-sulfur batteries. J. Mater. Chem. A 2018, 6, 19358-19370. [CrossRef]

83. Hu, N.; Lv, X.; Dai, Y.; Fan, L.; Xiong, D.; Li, X. SnO $2 /$ Reduced Graphene Oxide Interlayer Mitigating the Shuttle Effect of Li-S Batteries. ACS Appl. Mater. Interfaces 2018, 10, 18665-18674. [CrossRef] [PubMed]

84. Hwang, J.Y.; Kim, H.M.; Lee, S.K.; Lee, J.H.; Abouimrane, A.; Khaleel, M.A.; Belharouak, I.; Manthiram, A.; Sun, Y.K. High-Energy, High-Rate, Lithium-Sulfur Batteries: Synergetic Effect of Hollow $\mathrm{TiO}_{2}$-Webbed Carbon Nanotubes and a Dual Functional Carbon-Paper Interlayer. Adv. Energy Mater. 2016, 6, 1501480. [CrossRef]

85. Zhou, Y.; Zhou, C.; Li, Q.; Yan, C.; Han, B.; Xia, K.; Gao, Q.; Wu, J. Enabling Prominent High-Rate and Cycle Performances in One Lithium-Sulfur Battery: Designing Permselective Gateways for $\mathrm{Li}^{+}$Transportation in Holey-CNT/S Cathodes. Adv. Mater. 2015, 27, 3774-3781. [CrossRef] [PubMed]

86. Hao, Z.; Zeng, R.; Yuan, L.; Bing, Q.; Liu, J.; Xiang, J.; Huang, Y. Perovskite $\mathrm{La}_{0.6} \mathrm{Sr}_{0.4} \mathrm{CoO}_{3-\delta}$ as a new polysulfide immobilizer for high-energy lithium-sulfur batteries. Nano Energy 2017, 40, 360-368. [CrossRef]

87. Bao, J.; Zhang, X.; Fan, B.; Zhang, J.; Zhou, M.; Yang, W.; Hu, X.; Wang, H.; Pan, B.; Xie, Y. Ultrathin Spinel-Structured Nanosheets Rich in Oxygen Deficiencies for Enhanced Electrocatalytic Water Oxidation. Angew. Chem. Int. Ed. 2015, 54, 7399-7404. [CrossRef]

88. Gao, R.; Liu, L.; Hu, Z.; Zhang, P.; Cao, X.; Wang, B.; Liu, X. The role of oxygen vacancies in improving the performance of $\mathrm{CoO}$ as a bifunctional cathode catalyst for rechargeable $\mathrm{Li}-\mathrm{O}_{2}$ batteries. J. Mater. Chem. A 2015, 3, 17598-17605. [CrossRef] 
89. Bruix, A.; Füchtbauer, H.G.; Tuxen, A.K.; Walton, A.S.; Andersen, M.; Porsgaard, S.; Besenbacher, F.; Hammer, B.; Lauritsen, J.V. In Situ Detection of Active Edge Sites in Single-Layer $\mathrm{MoS}_{2}$ Catalysts. ACS Nano 2015, 9, 9322-9330. [CrossRef]

90. Bonaccorso, F.; Colombo, L.; Yu, G.; Stoller, M.; Tozzini, V.; Ferrari, A.C.; Ruoff, R.S.; Pellegrini, V. Graphene, related two-dimensional crystals, and hybrid systems for energy conversion and storage. Science 2015, 347, 1246501. [CrossRef]

91. Masurkar, N.; Thangavel, N.K.; Arava, L.M.R. CVD-Grown MoSe 2 Nanoflowers with Dual Active Sites for Efficient Electrochemical Hydrogen Evolution Reaction. ACS Appl. Mater. Interfaces 2018, 10, 27771-27779. [CrossRef]

92. Chhowalla, M.; Shin, H.S.; Eda, G.; Li, L.J.; Loh, K.P.; Zhang, H. The chemistry of two-dimensional layered transition metal dichalcogenide nanosheets. Nat. Chem. 2013, 5, 263-275. [CrossRef] [PubMed]

93. Liu, D.; Zhang, C.; Zhou, G.; Lv, W.; Ling, G.; Zhi, L.; Yang, Q.H. Catalytic Effects in Lithium-Sulfur Batteries: Promoted Sulfur Transformation and Reduced Shuttle Effect. Adv. Sci. 2018, 5, 1700270. [CrossRef] [PubMed]

94. Xu, H.; Yang, S.; Li, B. Ultrathin bismuth nanosheets as an efficient polysulfide catalyst for high performance lithium-sulfur batteries. J. Mater. Chem. A 2020, 8, 149-157. [CrossRef]

95. Wang, L.; Song, Y.H.; Zhang, B.H.; Liu, Y.T.; Wang, Z.Y.; Li, G.R.; Liu, S.; Gao, X.P. Spherical Metal Oxides with High Tap Density as Sulfur Host to Enhance Cathode Volumetric Capacity for Lithium-Sulfur Battery. ACS Appl. Mater. Interfaces 2020, 12, 5909-5919. [CrossRef]

96. Boyjoo, Y.; Shi, H.; Olsson, E.; Cai, Q.; Wu, Z.S.; Liu, J.; Lu, G.Q. Molecular-Level Design of Pyrrhotite Electrocatalyst Decorated Hierarchical Porous Carbon Spheres as Nanoreactors for Lithium-Sulfur Batteries. Adv. Energy Mater. 2020, 10, 2000651. [CrossRef]

97. Li, Z.; Zhang, S.; Zhang, J.; Xu, M.; Tatara, R.; Dokko, K.; Watanabe, M. Three-Dimensionally Hierarchical $\mathrm{Ni} / \mathrm{Ni}_{3} \mathrm{~S}_{2} / \mathrm{S}$ Cathode for Lithium-Sulfur Battery. ACS Appl. Mater. Interfaces 2017, 9, 38477-38485. [CrossRef]

98. Pu, J.; Shen, Z.; Zheng, J.; Wu, W.; Zhu, C.; Zhou, Q.; Zhang, H.; Pan, F. Multifunctional $\mathrm{Co}_{3} \mathrm{~S}_{4} @$ sulfur nanotubes for enhanced lithium-sulfur battery performance. Nano Energy 2017, 37, 7-14. [CrossRef]

99. He, J.; Hartmann, G.; Lee, M.; Hwang, G.S.; Chen, Y.; Manthiram, A. Freestanding $1 \mathrm{~T} \mathrm{MoS} 2 /$ graphene heterostructures as a highly efficient electrocatalyst for lithium polysulfides in Li-S batteries. Energy Environ. Sci. 2019, 12, 344-350. [CrossRef]

100. Hu, L.; Dai, C.; Lim, J.M.; Chen, Y.; Lian, X.; Wang, M.; Li, Y.; Xiao, P.; Henkelman, G.; Xu, M. A highly efficient double-hierarchical sulfur host for advanced lithium-sulfur batteries. Chem. Sci. 2018, 9, 666-675. [CrossRef]

101. Luo, L.; Chung, S.H.; Yaghoobnejad Asl, H.; Manthiram, A. Long-Life Lithium-Sulfur Batteries with a Bifunctional Cathode Substrate Configured with Boron Carbide Nanowires. Adv. Mater. 2018, 30, e1804149. [CrossRef] [PubMed]

102. He, J.; Chen, Y.; Manthiram, A. Vertical $\mathrm{Co}_{9} \mathrm{~S}_{8}$ hollow nanowall arrays grown on a Celgard separator as a multifunctional polysulfide barrier for high-performance Li-S batteries. Energy Environ. Sci. 2018, 11, 2560-2568. [CrossRef]

103. Chen, T.; Ma, L.; Cheng, B.; Chen, R.; Hu, Y.; Zhu, G.; Wang, Y.; Liang, J.; Tie, Z.; Liu, J. Metallic and polar Co9S8 inlaid carbon hollow nanopolyhedra as efficient polysulfide mediator for lithium-sulfur batteries. Nano Energy 2017, 38, 239-248. [CrossRef]

104. Lin, H.; Yang, L.; Jiang, X.; Li, G.; Zhang, T.; Yao, Q.; Zheng, G.W.; Lee, J.Y. Electrocatalysis of polysulfide conversion by sulfur-deficient $\mathrm{MoS}_{2}$ nanoflakes for lithium-sulfur batteries. Energy Environ. Sci. 2017, 10, 1476-1486. [CrossRef]

105. Gao, X.; Yang, X.; Li, M.; Sun, Q.; Liang, J.; Luo, J.; Wang, J.; Li, W.; Liang, J.; Liu, Y.; et al. Cobalt-Doped SnS2 with Dual Active Centers of Synergistic Absorption-Catalysis Effect for High-S Loading Li-S Batteries. Adv. Funct. Mater. 2019, 29, 1806724. [CrossRef]

106. Zhou, G.; Tian, H.; Jin, Y.; Tao, X.; Liu, B.; Zhang, R.; Seh, Z.W.; Zhuo, D.; Liu, Y.; Sun, J.; et al. Catalytic oxidation of $\mathrm{Li}_{2} \mathrm{~S}$ on the surface of metal sulfides for Li-S batteries. Proc. Nat. Acad. Sci. USA 2017, 114, 840-845. [CrossRef]

107. Lu, X.; Zhang, Q.; Wang, J.; Chen, S.; Ge, J.; Liu, Z.; Wang, L.; Ding, H.; Gong, D.; Yang, H.; et al. High performance bimetal sulfides for lithium-sulfur batteries. Chem. Eng. J. 2019, 358, 955-961. [CrossRef]

108. Zhong, Y.; Xia, X.; Shi, F.; Zhan, J.; Tu, J.; Fan, H.J. Transition Metal Carbides and Nitrides in Energy Storage and Conversion. Adv. Sci. 2016, 3, 1500286. [CrossRef] 
109. Ham, D.J.; Lee, J.S. Transition metal carbides and nitrides as electrode materials for low temperature fuel cells. Energies 2009, 2, 873-899. [CrossRef]

110. Peng, H.J.; Zhang, G.; Chen, X.; Zhang, Z.W.; Xu, W.T.; Huang, J.Q.; Zhang, Q. Enhanced electrochemical kinetics on conductive polar mediators for lithium-sulfur batteries. Angew. Chem. Int. Ed. 2016, 55, 12990-12995. [CrossRef]

111. Bao, W.; Su, D.; Zhang, W.; Guo, X.; Wang, G. 3D Metal Carbide@ Mesoporous Carbon Hybrid Architecture as a New Polysulfide Reservoir for Lithium-Sulfur Batteries. Adv. Funct. Mater. 2016, 26, 8746-8756. [CrossRef]

112. Pourali, Z.; Yaftian, M.R.; Sovizi, M.R. $\mathrm{Li}_{2} \mathrm{~S} /$ transition metal carbide composite as cathode material for high performance lithium-sulfur batteries. Mater. Chem. Phys. 2018, 217, 117-124. [CrossRef]

113. Liang, X.; Garsuch, A.; Nazar, L.F. Sulfur cathodes based on conductive MXene nanosheets for high-performance lithium-sulfur batteries. Angew. Chem. Int. Ed. 2015, 54, 3907-3911. [CrossRef] [PubMed]

114. Du, Z.; Chen, X.; Hu, W.; Chuang, C.; Xie, S.; Hu, A.; Yan, W.; Kong, X.; Wu, X.; Ji, H. Cobalt in nitrogen-doped graphene as single-atom catalyst for high-sulfur content lithium-sulfur batteries. J. Am. Chem. Soc. 2019, 141, 3977-3985. [CrossRef] [PubMed]

115. Lim, W.G.; Mun, Y.; Cho, A.; Jo, C.; Lee, S.; Han, J.W.; Lee, J. Synergistic Effect of Molecular-Type Electrocatalysts with Ultrahigh Pore Volume Carbon Microspheres for Lithium-Sulfur Batteries. ACS Nano 2018, 12, 6013-6022. [CrossRef]

116. Wang, N.; Chen, B.; Qin, K.; Liu, E.; Shi, C.; He, C.; Zhao, N. Rational design of $\mathrm{Co}_{9} \mathrm{~S}_{8} / \mathrm{CoO}_{\text {heterostructures }}$ with well-defined interfaces for lithium sulfur batteries: A study of synergistic adsorption-electrocatalysis function. Nano Energy 2019, 60, 332-339. [CrossRef]

117. Wei, Y.; Kong, Z.; Pan, Y.; Cao, Y.; Long, D.; Wang, J.; Qiao, W.; Ling, L. Sulfur film sandwiched between few-layered $\mathrm{MoS}_{2}$ electrocatalysts and conductive reduced graphene oxide as a robust cathode for advanced lithium-sulfur batteries. J. Mater. Chem. A 2018, 6, 5899-5909. [CrossRef]

118. Zhou, H.Y.; Sui, Z.Y.; Amin, K.; Lin, L.W.; Wang, H.Y.; Han, B.H. Investigating the Electrocatalysis of a $\mathrm{Ti}_{3} \mathrm{C}_{2} /$ Carbon Hybrid in Polysulfide Conversion of Lithium-Sulfur Batteries. ACS Appl. Mater. Interfaces 2020, 12, 13904-13913. [CrossRef]

119. Wu, Y.; Deng, J.; Zhou, Y.; Huang, Y.; Li, Y. Molybdenum carbide nanostructures for electrocatalytic polysulfide conversion in lithium-polysulfide batteries. Nanoscale Horiz. 2020, 5, 501-506. [CrossRef]

120. Razaq, R.; Sun, D.; Xin, Y.; Li, Q.; Huang, T.; Zheng, L.; Zhang, Z.; Huang, Y. Enhanced kinetics of polysulfide redox reactions on $\mathrm{Mo}_{2} \mathrm{C} / \mathrm{CNT}$ in lithium-sulfur batteries. Nanotechnology 2018, 29, 295401. [CrossRef]

121. Cheng, X.B.; Huang, J.Q.; Zhang, Q. Li metal anode in working lithium-sulfur batteries. J. Electrochem. Soc. 2017, 165, A6058. [CrossRef]

122. Gruber, P.W.; Medina, P.A.; Keoleian, G.A.; Kesler, S.E.; Everson, M.P.; Wallington, T.J. Global lithium availability: A constraint for electric vehicles? J. Ind. Ecol. 2011, 15, 760-775. [CrossRef]

123. Swain, B. Recovery and recycling of lithium: A review. Sep. Purif. Technol. 2017, 172, 388-403. [CrossRef]

124. Kavanagh, L.; Keohane, J.; Garcia Cabellos, G.; Lloyd, A.; Cleary, J. Global lithium sources-Industrial use and future in the electric vehicle industry: A review. Resources 2018, 7, 57. [CrossRef]

125. Tran, M.K.; Rodrigues, M.T.F.; Kato, K.; Babu, G.; Ajayan, P.M. Deep eutectic solvents for cathode recycling of Li-ion batteries. Nat. Energy 2019, 4, 339-345. [CrossRef]

126. Miroshnikov, M.; Kato, K.; Babu, G.; Thangavel, N.K.; Mahankali, K.; Hohenstein, E.; Wang, H.; Satapathy, S.; Divya, K.P.; Asare, H.; et al. Made From Henna! A Fast-Charging, High-Capacity, and Recyclable Tetrakislawsone Cathode Material for Lithium Ion Batteries. ACS Sustain. Chem. Eng. 2019, 7, 13836-13844. [CrossRef]

(C) 2020 by the authors. Licensee MDPI, Basel, Switzerland. This article is an open access article distributed under the terms and conditions of the Creative Commons Attribution (CC BY) license (http://creativecommons.org/licenses/by/4.0/). 